\title{
A genome-wide screen to identify transcription factors expressed in pelvic ganglia of the lower urinary tract
}

\section{Carrie B. Wiese ${ }^{1}$, Sara Ireland ${ }^{1}$, Nicole L. Fleming ${ }^{1}$, Jing Yu ${ }^{2}$, M. Todd Valerius ${ }^{3}$, Kylie Georgas ${ }^{4}$, Han Sheng Chiu ${ }^{4}$, Jane Brennan ${ }^{5}$, Jane Armstrong ${ }^{5}$, Melissa H. Little ${ }^{4}$, Andrew P. McMahon ${ }^{6,7}$ and E. Michelle Southard-Smith ${ }^{1}$ *}

\author{
Division of Genetic Medicine, Department of Medicine, Vanderbilt University School of Medicine, Nashville, TN, USA \\ ${ }^{2}$ Department of Cell Biology, University of Virginia School of Medicine, Charlottesville, VA, USA \\ ${ }^{3}$ Department of Surgery, The Transplant Institute, Beth Israel Deaconess Medical Center, Harvard Medical School, Boston, MA, USA \\ 4 Institute for Molecular Bioscience, University of Queensland, Brisbane, QLD, Australia \\ ${ }^{5}$ GUDMAP Editorial Office, Center for Integrative Physiology, University of Edinburgh, Edinburgh, UK \\ ${ }^{6}$ Department of Stem Cell and Regenerative Biology, Harvard Stem Cell Institute, Harvard University, Cambridge, MA, USA \\ Department of Molecular and Cellular Biology, Harvard Stem Cell Institute, Harvard University, Cambridge, MA, USA
}

\section{Edited by:}

Margaret A. Vizzard, University of Vermont College of Medicine, USA

\section{Reviewed by:}

Hideki Enomoto, RIKEN, Japan

Miles Epstein, University of

Wisconsin-Madison, USA

Marthe J. Howard, University of

Toledo Health Sciences Campus, USA

*Correspondence:

E. Michelle Southard-Smith, Division of Genetic Medicine, Department of Medicine, Vanderbilt University, 2215 Garland Avenue, 529 Light Hall, Nashville, TN 37232-0275, USA. e-mail: michelle.southardsmith@vanderbilt.edu
Relative positions of neurons within mature murine pelvic ganglia based on expression of neurotransmitters have been described. However the spatial organization of developing innervation in the murine urogenital tract (UGT) and the gene networks that regulate specification and maturation of neurons within the pelvic ganglia of the lower urinary tract (LUT) are unknown. We used whole-mount immunohistochemistry and histochemical stains to localize neural elements in 15.5 days post coitus (dpc) fetal mice. To identify potential regulatory factors expressed in pelvic ganglia, we surveyed expression patterns for known or probable transcription factors (TF) annotated in the mouse genome by screening a wholemount in situ hybridization library of fetal UGTs. Of the 155 genes detected in pelvic ganglia, 88 encodeTFs based on the presence of predicted DNA-binding domains. Neural crest (NC)derived progenitors within the LUT were labeled by Sox10, a well-known regulator of NC development. Genes identified were categorized based on patterns of restricted expression in pelvic ganglia, pelvic ganglia and urethral epithelium, or pelvic ganglia and urethral mesenchyme. Gene expression patterns and the distribution of Sox10+, Phox2b+, Hu+, and PGP9.5+ cells within developing ganglia suggest previously unrecognized regional segregation of Sox10+ progenitors and differentiating neurons in early development of pelvic ganglia. Reverse transcription-PCR of pelvic ganglia RNA from fetal and post-natal stages demonstrated that multiple TFs maintain post-natal expression, although Pax3 is extinguished before weaning. Our analysis identifies multiple potential regulatory genes including TFs that may participate in segregation of discrete lineages within pelvic ganglia. The genes identified here are attractive candidate disease genes that may now be further investigated for their roles in malformation syndromes or in LUT dysfunction.

Keywords: pelvic ganglia, autonomic nervous system, transcription factor, in situ hybridization, lower urinary tract, genitourinary, mouse, Genitourinary Development Molecular Anatomy Project

\section{INTRODUCTION}

Autonomic innervation of the urogenital tract (UGT) controls many fundamental functions including release of hormones from the adrenal, regulation of renal blood flow, peristalsis of urine along the ureters to the bladder, and coordination of urine release from the bladder, as well as sexual arousal. These critical functions can be disrupted by age, disease, or surgical interventions. Anatomy of these neural structures is essential for urological training and efforts to readily visualize these critical elements have been a focus in recent years (Lee et al., 2010; Taylor et al., 2010).

Anatomical study of urogenital autonomic ganglia and their accompanying peripheral nerve fibers has been achieved primarily in adult human biopsies and fetal tissues (Jen et al., 1995; Dixon et al., 1998; Yucel et al., 2004). These human studies are challenged by consistency in collection, availability of multiple samples at equivalent developmental stages, and comparison of genetically heterogeneous individuals. However, they have succeeded in defining the location of nerve fibers in the developing urethral sphincter (Yucel et al., 2004; Karam et al., 2005; Wallner et al., 2009), and mapping neuromuscular junctions as well as generally localizing neuronal and glial elements (Kluck, 1980; Wadhwa and Bijlani, 1983; Elbadawi, 1991; Yucel et al., 2004).

Pelvic innervation in humans consists of a diffuse pelvic plexus, while that of rodents consists of large paired pelvic ganglia that flank the urethra. The ready ability to visualize pelvic ganglia in mice has led to detailed neurochemical and anatomical analyses aimed at identifying the locations and distributions of discrete neuronal subtypes within pelvic neural elements in rodents (Yan 
and Keast, 2008). Such efforts have defined the topography of nerve fibers and defined differential reactivity to neuronal antigens including acetylcholinesterase (AChE), dopamine $\beta$-hydroxylase $(\mathrm{D} \beta \mathrm{H})$, tyrosine hydroxylase $(\mathrm{TH})$, ubiquitin carboxy-terminal hydrolase L1 (PGP9.5), neuronal nitric oxide synthase (nNOS), vasoactive intestinal peptide (VIP), and neuropeptide Y (NPY) within the bladder wall and adjacent pelvic ganglia (Wanigasekara et al., 2003; Keast, 2006; Yan and Keast, 2008; Girard et al., 2010). As a result neurotransmitter expression within subsets of pelvic ganglia neurons is known and some of the physiological properties of pelvic ganglia based on immunohistochemical coding of multiple neurotransmitters have been defined (Keast, 2006; Jobling and Lim, 2008; Tompkins et al., 2010).

Unfortunately, the factors that control the development of pelvic innervation are much less well understood. Neurotrophins and glial cell-derived neurotrophic factors do affect cell migration and neurite outgrowth from pelvic ganglia neurons like they do elsewhere in the peripheral nervous system, although initial studies suggest their effects are age and neuron-type dependent (Stewart et al., 2008). However, nothing is known about regulatory networks that control specification of pelvic neuron subtypes or regulate their post-natal maturation. Advances in regenerative strategies to repair damaged pelvic neural inputs are much more likely to be achieved with greater knowledge of processes integral to normal development of pelvic innervation.

High throughput screens to visualize expression of potential transcriptional regulators or receptors and their ligands are one means to identify key regulatory molecules during organogenesis (Gray et al., 2004; Choi et al., 2006; Kong et al., 2006; Mugford et al., 2009). To discover gene networks most likely to control pelvic innervation during development, we surveyed a genome scale whole-mount in situ hybridization (WISH) library of fetal mouse UGT hybridized to probes for 1379 genes including 921 transcription factors (TFs) annotated in the mouse genome (Gray et al., 2004). We complemented the survey by identifying the locations of developing neurons and glia in whole-mount fetal UGT. Our study has identified a subset of genes that are expressed in the developing pelvic ganglia, some of which maintained their expression into post-natal maturation. This analysis identifies urological candidate disease genes and lays a foundation for future study of TF networks and gene expression levels in congenital lower urinary tract (LUT) defects, urological disease, and aging.

\section{MATERIALS AND METHODS ANIMALS}

All animal protocols were approved by the Institutional Animal Care and Use Committee at Vanderbilt University. Timed matings were set to obtain staged mouse embryos, designating the morning of plug formation as 0.5 day post coitus (dpc). Post-natal stages were designated with the date of birth as $\mathrm{P} 0$ and $\mathrm{P} 2$ as the second day after birth. Swiss Webster outbred mice were used to obtain embryos for whole-mount and sectional in situ. Sox10-H2BVenus mice were maintained as congenic lines on the $\mathrm{C} 3 \mathrm{HeB} / \mathrm{FeJ}$ inbred strain and bred as previously described to obtain staged litters (Corpening et al., 2011). Phox $2 b$-H2BCFP mice were maintained by crosses to $\mathrm{C} 57 \mathrm{BL} / 6 \mathrm{~J} \times \mathrm{C} 3 \mathrm{HeBFeJ} \mathrm{F}_{1}$ animals (Corpening et al., 2008).

\section{WHOLE-MOUNT IMMUNOHISTOCHEMISTRY OF FETAL LUT}

Whole-mount immunohistochemistry (IHC) methods were modified from the previously published protocols (Mark et al., 1993; Bamforth et al., 2001; van de Putte et al., 2007). Briefly, fetal LUTs were dissected from $15.5 \mathrm{dpc}$ wild-type mice and fixed at $4^{\circ} \mathrm{C}$ in $4 \%$ paraformaldehyde overnight. Endogenous peroxidase activity was inactivated with $3 \% \mathrm{H}_{2} \mathrm{O}_{2}, 80 \%$ methanol, and $20 \%$ dimethylsulfoxide (DMSO) solution for $3 \mathrm{~h}$. Washes were performed with Tris-buffered saline (TBS) containing 1\% Tween-20 and blocked in TBS containing 1\% Tween-20 and 5\% skim milk. Samples were incubated with either rabbit anti-PGP9.5 (1:4000, Biogenesis), mouse monoclonal anti-2H3/neurofilament (NF; 1:100, Developmental Studies Hybridoma Bank), sheep anti-TH (1:100, Chemicon), or rabbit anti-vesicular acetylcholine transporter (VAChT; 1:1000, Synaptic Systems) antibody diluted in block containing $5 \%$ DMSO and $0.1 \%$ sodium azide for 3 days at room temperature. Primary antibodies were detected with HRP-conjugated donkey anti-rabbit IgG (1:1000), HRP-conjugated donkey antimouse IgG (1:100), and HRP-conjugated donkey anti-sheep IgG (1:200), respectively (Jackson Immuno Research). Visualization was achieved with 4-chloro-1-naphthol solution (Sigma-Aldrich) according to the manufacturer's instructions.

\section{SECTIONAL EMBRYONIC IMMUNOHISTOCHEMISTRY}

Whole-mount 15.5dpc Sox10-H2BVenus+ and Phox $2 b$-H2BCFP+ double transgenic embryos were fixed at $4^{\circ} \mathrm{C}$ in neutral buffered formalin for $5 \mathrm{~h}$ and washed with $1 \times$ PBS before incubating in $30 \%$ sucrose at $4^{\circ} \mathrm{C}$ overnight. The samples were cryo-embedded by rapid freezing on dry ice after submerging into OCT tissue freezing media (Tissue Tek). A Lecia CM1900 cryostat was utilized to generate $18 \mu \mathrm{m}$ thick sections onto treated slides, which were heated on a slide warmer for $30 \mathrm{~min}$. Melted freezing media was removed by washes in $1 \times \mathrm{PBS}+0.5 \%$ Triton $\mathrm{X}-100$ and the sections were blocked for $1 \mathrm{~h}$ at room temperature in $1 \times$ PBS containing $0.1 \%$ Triton $\mathrm{X}-100,5 \%$ heat-inactivated normal donkey serum (Jackson Immuno Research), and 1\% bovine serum albumin. Sections were incubated overnight at $4^{\circ} \mathrm{C}$ with $\mathrm{Hu}$ (Kiers et al., 1991; Fairman et al., 1995, 1:800) and rabbit anti-PGP9.5 (1:4000, Biogenesis) antibodies diluted in block. Primary antibodies were detected with texas red-conjugated donkey anti-human (1:100, Jackson Immuno Research) and Cy5-conjugated donkey anti-rabbit (1:400, Jackson Immuno Research). Sections were incubated with secondary antibodies for $1 \mathrm{~h}$ at room temperature, followed by $1 \times$ PBS washes then mounted in Aqua-Poly/Mount (Polysciences, Inc.).

\section{ACETYLCHOLINESTERASE STAINING}

Fetal LUTs were dissected from $15.5 \mathrm{dpc}$ wild-type mice and wholemount AChE enzyme histochemistry was performed essentially as previously described (Enomoto et al., 1998).

\section{IN SITU HYBRIDIZATION}

Whole-mount and sectional in situ hybridization were performed as previously described (Little et al., 2007; Mugford et al., 2009) and as listed in detail on the GUDMAP gene expression database (http://www.gudmap.org; see http://www.gudmap.org/research/protocols/McMahon.html 
and http://www.gudmap.org/research/protocols/Little.html for experimental details). Full details of the screen for mammalian TF expression are described elsewhere (Yu et al., 2012).

\section{IMAGING}

Whole UGT samples were further dissected after colorimetric development to facilitate imaging of the LUT. Samples were imaged in whole-mount using a DAGE DC330 Camera mounted on a Leica MZ12.5 stereomicroscope in either dark field or bright field views. Images were taken at either 25 or $50 \times$ magnification. Images were limited to $300 \mathrm{dpi}$, cropped in Adobe Photoshop and adjusted for brightness and contrast to provide the best two-dimensional representation of each gene expression pattern. Sox10-H2BVenus whole-mount bladder and urethra images were captured using Zeiss Stereo Lumar.V12 fluorescence stereomicroscope equipped with a Q-Imaging 4000R digital camera and software. The lateral images of $14.5 \mathrm{dpc}, 15.5 \mathrm{dpc}, \mathrm{P} 2, \mathrm{P} 10, \mathrm{P} 21$ LUT were taken at $25-50 \times$ magnification. Confocal microscopy of sectional IHC was performed on a Zeiss Scanning Microscope LSM510 using CFP, YFP Rhodamine, and Cy5 long pass filters as previously described (Corpening et al., 2008, 2011) to visualize transgenic expression of CFP and YFP in combination with neuronal antigens detected by antibodies.

\section{REVERSE TRANSCRIPTION-PCR}

Using a Zeiss Stereo Lumar.V12 fluorescence stereomicroscope, YFP positive pelvic ganglia were dissected from Sox10-H2BVenus transgenic mice then stored in RNAlater at $4^{\circ} \mathrm{C}$. To ensure sufficient RNA yield from tissue isolates at each stage pelvic ganglia were pooled from $6,5,2,4$, and 3 individual animals at $14.5 \mathrm{dpc}, 15.5 \mathrm{dpc}, \mathrm{P} 2, \mathrm{P} 10$, and $\mathrm{P} 21$, respectively. Total RNA was purified from isolated pelvic ganglia by homogenizing tissues in TRIzol (Invitrogen) and extracting RNA as previously described (Iwashita et al., 2003; Corpening et al., 2011). RNA was treated with DNase I and purified via RNeasy kit (Qiagen). Reverse transcription (RT) was performed using a high capacity cDNA RT kit $(\mathrm{ABI})$ with a $50 \mu \mathrm{L}$ reaction and starting input of $160 \mathrm{ng}$ of RNA. Subsequently cDNA (3 ng input per reaction) was amplified using routine PCR conditions. PCR was done with limiting numbers of thermocycles $(<30)$ during exponential phases of amplification to provide an estimate of relative gene expression with all the reactions for the different stages of a particular gene assay performed and evaluated in parallel. RT-PCR product sizes were evaluated by non-denaturing polyacrylamide gel electrophoresis.

\section{RESULTS \\ WHOLE-MOUNT VISUALIZATION OF NEURAL ELEMENTS IN THE FETAL MOUSE UGT}

The distribution of neural elements in the fetal murine UGT has not previously been described in whole-mount. Typically images of these structures are derived from small pieces of dissected material or tissue sections subjected to IHC to reveal the positions of particular cell-type specific antigens. However, axonal projections are not always evident in single sections, thus to establish a baseline for identifying genes expressed in pelvic neural elements and gain an overall spatial perspective of condensing autonomic ganglia, we implemented whole-mount immunohistochemical detection using immunoreagents to detect neuronal cell types including Neurofilament (NF) and Protein gene product 9.5 (PGP9.5). NF comprises a major element of the axonal cytoplasm in differentiated neurons so that detection of this antigen by IHC labels cell processes. PGP9.5 protein, which derives from the gene Uchll, is an ubiquitin hydrolase that is found both in the cell soma as well as in axonal processes (Thompson et al., 1983; Young et al., 2003; Corpening et al., 2011). While PGP9.5 is often used as generic marker to identify mature neurons, it also labels cells in early phases of neuronal differentiation in both the central and peripheral nervous systems (Sidebotham et al., 2001; Sakurai et al., 2006; D'Autreaux et al., 2007). The IHC distribution of NF and PGP9.5 revealed discrete clusters of developing neurons in the forming sympathetic chain at the dorsal mid-line of the UGT (Figures 1A,B). Fibrous staining of axonal processes extending from these condensations laterally was evident medial to the kidneys and at more rostral levels near the adrenals. At the level of the urethra, staining of axonal processes extending from the pelvic ganglia that wrapped dorsally behind the urethra was also strongly labeled by both NF and PGP9.5. Moreover a dense network of PGP9.5 reactive processes was already evident in the bladder wall at $15.5 \mathrm{dpc}$ extending toward the bladder dome in both lateral and anterior views (Figures $1 \mathbf{A}^{\prime}, \mathbf{A}^{\prime \prime \prime}, \mathbf{B}^{\prime}, \mathbf{B}^{\prime \prime \prime}$ ). A summary diagram depicting the distribution of neural elements detected in the UGT relative to the developing fetal organs at $15.5 \mathrm{dpc}$ is provided in Figure 1C.

Prior studies have reported extensive cholinergic innervation in sectioned UGT tissues of adult mice (Yan and Keast, 2008). To begin identifying the positions of developing cholinergic neurons, we initially applied whole-mount acetylcholinesterase (AChE) histochemistry, a robust detection method that has been used extensively to visualize cholinergic neurons within enteric ganglia of the intestinal wall (Enomoto et al., 1998). AChE strongly labels neuronal cell bodies as well as their processes but is not restricted to cholinergic neurons (Soreq and Seidman, 2001). AChE histochemistry extensively labeled axonal processes and ganglia in the fetal UGT at 15.5dpc (Figure 2A). Processes connecting the adrenal ganglia, sympathetic ganglia, and kidney pelvis were strongly labeled as well as neuronal bodies within the pelvic ganglia flanking the urethra. The bladder wall at $15.5 \mathrm{dpc}$ contained large numbers of AChE+ neural fibers that were primarily evident in lateral areas adjacent to the flanking blood vessels. This distribution contrasts to the much broader distribution in the bladder dome detected by PGP9.5 IHC and suggests either that PGP9.5 reactivity detects a population of early differentiating neurons expressing a different neurotransmitter in the medial anterior bladder wall or that accumulation of AChE activity has not reached sufficient levels for detection by this staining method.

To visualize specific neuronal populations in the developing UGT, we examined the distribution of cholinergic neurons labeled by VAChT and noradrenergic neurons labeled by TH (Wanigasekara et al., 2003). VAChT co-localizes with choline acetyltransferase in cholinergic neurons and has been used extensively as a surrogate marker for cholinergic neurons (Arvidsson et al., 1997; Ichikawa et al., 1997). VAChT was detected in the forming ganglia of the sympathetic chain and within dorsal celiac ganglia flanking the mid-line between the developing kidneys (Figure 2B). 


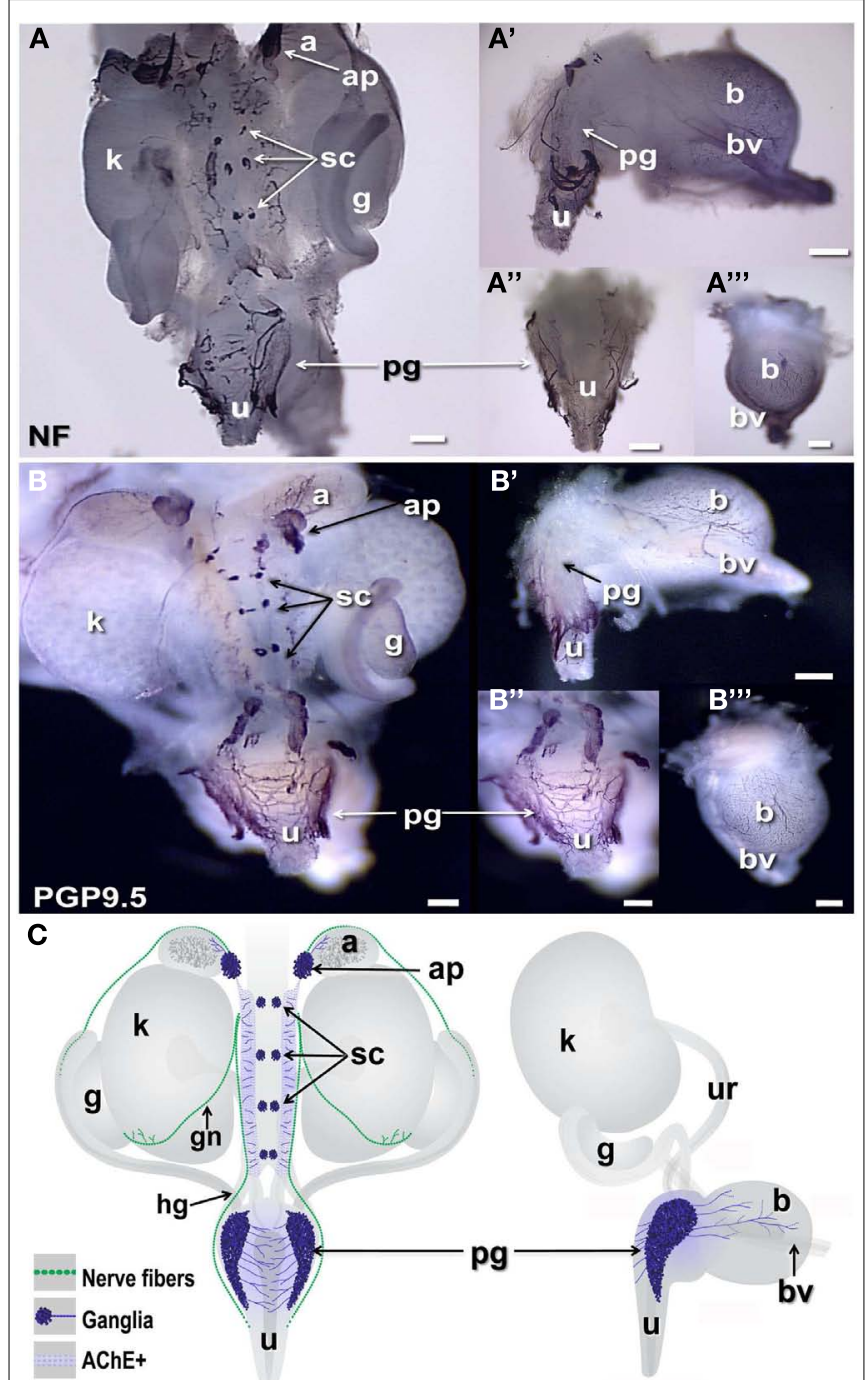

FIGURE 1 | Distribution of neural elements in fetal mouse LUT. Dorsal, lateral, and anterior views of whole-mount urogenital tract (UGT) processed to detect neuronal antigens are shown. (A) Positions of peripheral ganglia and nerve fibers are labeled by whole-mount IHC in female $15.5 \mathrm{dpc}$ fetal LUT stained for neurofilament (NF). (B) Whole-mount IHC for PGP9.5 similarly stains both peripheral ganglia and nerve processes at this stage in female LUT. Dorsal views of the intact UGT are shown for each antigen. Lateral views of dissected bladder with attached urethra are shown $\left(\mathbf{A}^{\prime}, \mathbf{B}^{\prime}\right)$. Dorsal views of the urethra $\left(\mathbf{A}^{\prime \prime}, \mathbf{B}^{\prime \prime}\right)$ and anterior views of the bladder $\left(\mathbf{A}^{\prime \prime \prime}, \mathbf{B}^{\prime \prime \prime}\right)$ show relative positions of the pelvic ganglia to these structures. (C) Schematic diagrams of fetal mouse UGT at $15.5 \mathrm{dpc}$ summarize elements of autonomic innervation detected by $\mathrm{IHC}$ in dark blue. Axonal processes of efferent innervation that are accompanied by NC-derived peripheral glia are shown in green. In dorsal views (left), the adrenal plexus extends processes into the NC-derived medulla (dark gray) of the adrenal. Sympathetic chain ganglia at this stage reside as tight clusters medially between the kidneys. Neurites from bilateral pelvic ganglia flanking the urethra extend processes toward the center of the dorsal urethra. When viewed laterally (right) neurites also extend from pelvic ganglia and out toward the bladder dome along blood vessels that flank the bladder. (a, adrenal; ap, adrenal plexus; $b$, bladder; bv, blood vessel; g, gonad; gn, gonadal nerve; hg, hypogastric nerve; k, kidney; pg, pelvic ganglia; sc, sympathetic chain; u, urethra; ur, ureter; scale bar $=300 \mu \mathrm{m}$ ).
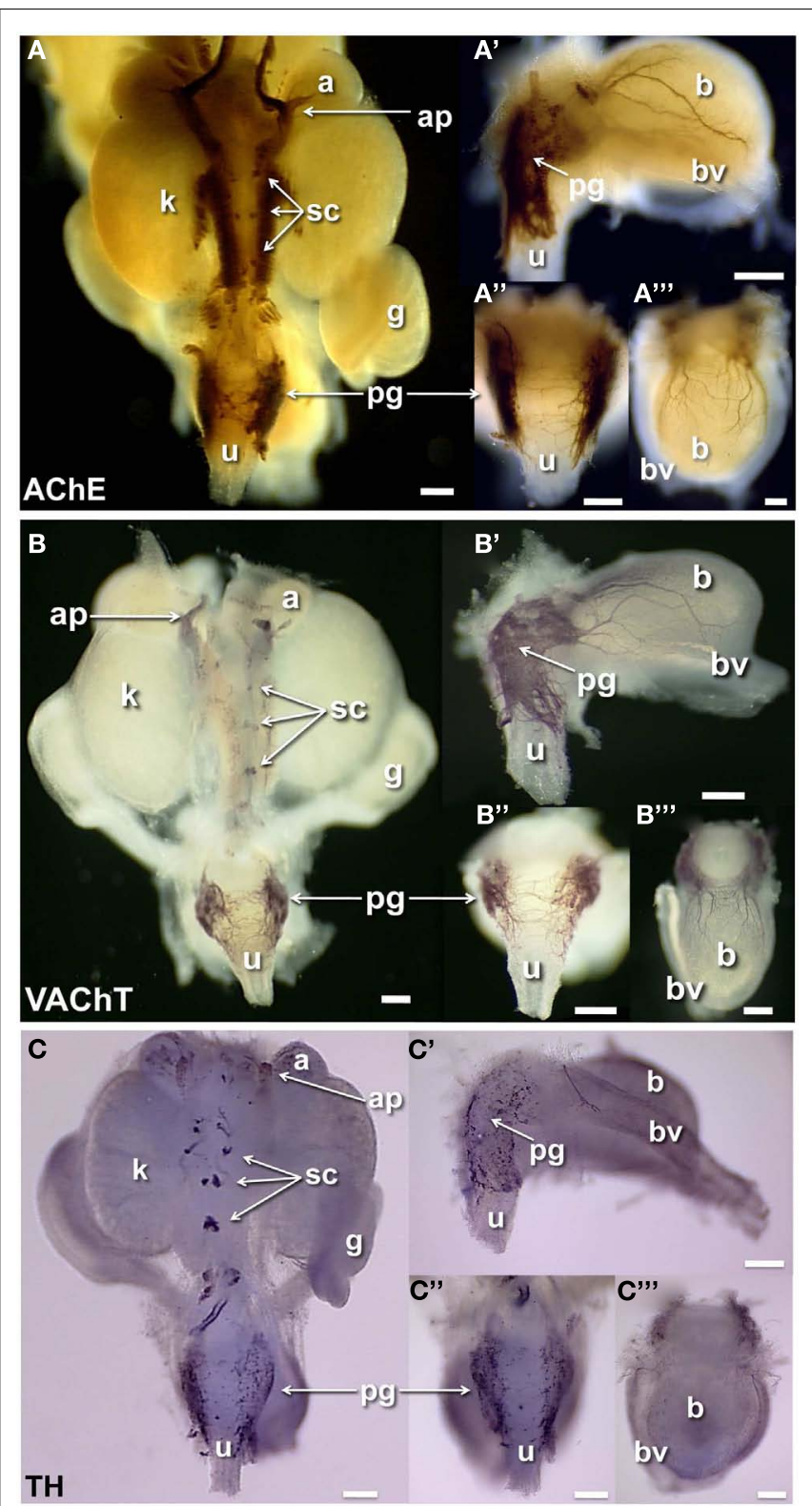

FIGURE 2 | Distribution of cholinergic and noradrenergic elements in fetal mouse LUT. Whole-mount images of male $15.5 \mathrm{dpc}$ fetal UGT samples stained by AChE histochemistry localizes primarily cholinergic innervation and some other neuronal subtypes (A). IHC staining of female $15.5 \mathrm{dpc}$ fetal LUT detects specifically cholinergic VAChT+ neurons (B). IHC staining of female LUT detects sympathetic noradrenergic innervation labeled by tyrosine hydroxylase immunoreactivity (C). (A-C) Consist of whole-mount images of $15.5 \mathrm{dpc}$ urogenital tissues including dorsal views (A-C), lateral views of bladder $\left(\mathbf{A}^{\prime}-\mathbf{C}^{\prime}\right)$, dorsal views of urethra $\left(\mathbf{A}^{\prime \prime}-\mathbf{C}^{\prime \prime}\right)$, and anterior view of bladder ( $\left.\mathbf{A}^{\prime \prime \prime}-\mathbf{C}^{\prime \prime \prime}\right)$. (a, adrenal; ap, adrenal plexus; b, bladder; bv, blood vessel; g, gonad; k, kidney; pg, pelvic ganglia; sc, sympathetic chain; u, urethra; scale bar $=300 \mu \mathrm{m}$ ).

At $15.5 \mathrm{dpc}$ pelvic ganglia were strongly VAChT+ and numerous $\mathrm{VAChT}+$ fibers were present in the dorsal aspect of the urethra. Numerous VAChT + fibers were also evident in the bladder in both 
lateral and anterior views (Figures $\mathbf{2 B}, \mathbf{B}^{\prime}, \mathbf{B}^{\prime \prime \prime}$ ). While VAChT was observed only in the adrenal plexus, $\mathrm{TH}$ immunoreactivity labeled both the adrenal medulla and as well as noradrenergic neurons of the adrenal plexus (Figure 2C). Noradrenergic neurons labeled by $\mathrm{TH}$ immunoreactivity were also detected in the forming ganglia of the sympathetic chain and in isolated cells throughout the pelvic ganglia as well as in a few scattered cell bodies at the dorsal aspect of the urethra. While VAChT had extensively labeled fibers in the developing bladder, $\mathrm{TH}$ reactivity in the bladder wall, was barely discernable when viewed in whole-mount. $\mathrm{TH}+$ cells were faintly visible in lateral and anterior views (Figures $2 \mathbf{C}^{\prime}, \mathbf{C}^{\prime \prime \prime}$ ) and were observed most frequently in the lateral bladder wall near the flanking blood vessels unlike the labeling for NF and PGP9.5 that was prominent in lateral areas of the bladder as well as the forming bladder dome.

To visualize neural crest (NC)-derived progenitors, we applied WISH to localize Sox 10 expression in $15.5 \mathrm{dpc}$ fetal LUT (Figure 3 ). Sox10 is a TF that is essential for formation of NC and for development of the autonomic nervous system (Britsch et al., 2001). Sox10 is initially expressed by multi-potent progenitors that generate both neurons and glia in the periphery (Morrison et al., 1999; White et al., 2001; Kim et al., 2003; Corpening et al., 2011). Sox10+ progenitors have been documented in cranial ganglia, dorsal root ganglia, sympathetic ganglia, sciatic nerve, and enteric ganglia (Britsch et al., 2001; Paratore et al., 2001; Aquino et al., 2006; Walters et al., 2010; Corpening et al., 2011). As development of the peripheral nervous system proceeds, Sox10 becomes restricted to glial cells. We observed Sox10 mRNA at high levels in regions of the LUT that coincided with known positions of NC-derived cell types (adrenal medulla) and autonomic peripheral ganglia (celiac ganglia, pelvic ganglia). In addition Sox10 was also expressed in discrete cells within the bladder body and the urethra (Figure 3 ). The punctate distribution of individual Sox $10+$ cells in the urethra and bladder wall that we observed likely represents peripheral glial cells that accompany axonal processes in these structures since Sox10 is down-regulated in differentiating neurons. The images shown were allowed to develop for substantial periods of time in order to detect all possible Sox10+ cells present in the bladder and urethra. Samples developed for shorter time periods in BM purple substrate were also obtained (Figures 3D,E) and exhibited comparable distributions of cells in the bladder wall and urethra. Interestingly these under-developed samples revealed that the highest density of cells transcribing Sox10 is in a central region near the apex of the triangular pelvic ganglia. Previous analyses of NC-derived peripheral ganglia have not detected regional differences in intensity or distribution of Sox10 staining but generally have been more focused on neuronal markers that are expressed after Sox10 down regulates.

\section{SURVEY TO IDENTIFY GENES EXPRESSED IN FETAL PELVIC GANGLIA}

Networks of TF expression that play critical roles in patterning and neurogenesis have been investigated in the central nervous system (Gray et al., 2004; Magdaleno et al., 2006; Fu et al., 2009). Some TFs that are essential for normal development of peripheral autonomic ganglia in the intestine including Sox 10, Phox $2 b$, and Hand 2 have been identified through analysis of disease models (SouthardSmith et al., 1998; Pattyn et al., 1999; D’Autreaux et al., 2007; Hendershot et al., 2007; Lei and Howard, 2011). However detailed knowledge of gene networks that participate in development of pelvic autonomic ganglia is lacking. And, to date, expression of only a handful of TFs [cJun (Nangle and Keast, 2009; Peddie and Keast, 2011), Stat (Bella et al., 2007), ER $\alpha, E R \beta$ (Papka et al., 2001), cFOS (Fang et al., 2000), androgen receptor (Schirar et al., 1997)] has been identified in pelvic ganglia. To identify potential regulatory networks that are expressed during formation of pelvic neural elements, we screened a genome scale WISH library comprised of intact mouse $15.5 \mathrm{dpc}$ fetal UGTs available through the GUDMAP resource (McMahon et al., 2008; Mugford et al., 2009;
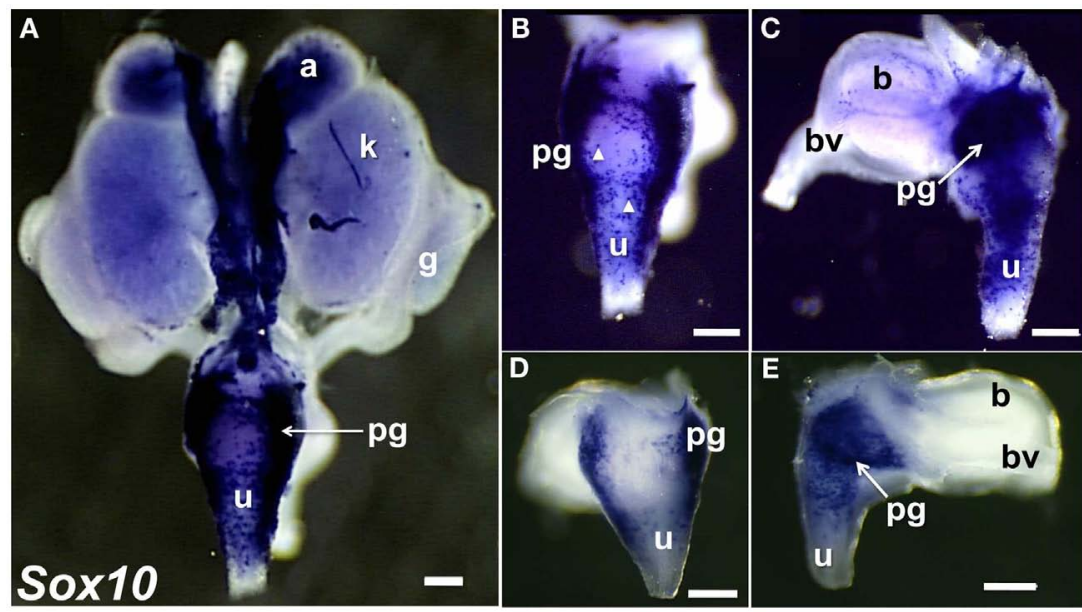

FIGURE 3 | Distribution of Sox10+ NC-derived progenitors in fetal mouse LUT. Whole-mount images of $15.5 \mathrm{dpc}$ UGT hybridized with anti-sense probes to detect Sox10 expression are shown. NC-derived cells are strongly labeled in dorsal view of entire UGT (A), dorsal view of urethra (B), and lateral view of bladder (C). Arrowheads highlight stained single cells visible in the dorsal view of the urethra and lateral view of the bladder. (GUDMAP Probe MTF511,
MGI:3506241, scale bar $=300 \mu \mathrm{m})$. Images of $15.5 \mathrm{dpc}$ UGT samples developed for a shorter period of time to discriminate regions of high versus low Sox10 expression are shown (D,E). Sox10+ progenitors are present in dorsal urethra [(D), 50x] and in pelvic ganglia viewed laterally (E). Note the high intensity of Sox10 expression within the interior region of the pelvic ganglia (arrow). GUDMAP probe MTF511, MGI:3506241. Scale bar $=300 \mu \mathrm{m}$. 
Harding et al., 2011). Among 1379 gene expression patterns examined, we identified 155 genes that exhibited definitive expression within pelvic ganglia (Table 1). Among these we sought to identify that subset of genes encoding TFs. Two prior studies relied on the presence of DNA-binding domains as a criteria to identify TF genes (Gray et al., 2004; Lee et al., 2007). Both studies focused on the presence of DNA-binding domains as a criterion though each used a slightly different method to refine their selections. More recent efforts have focused this list to the most likely subset of DNA-binding transcriptional regulators based on consensus overlap of both lists (Yu et al., 2012). Using this selective list, we determined that 88 of the original 155 expressed in pelvic ganglia are TFs (asterisked gene names Table 1). Comprehensive details of gene name and in situ probe identifiers for samples in which pelvic ganglia expression was scored as definitely present or not detected by WISH in this survey are provided in Table S1 in Supplementary Material. Both male and female fetal UGTs were evaluated for expression of TFs. For those samples where pelvic ganglia expression was detected, technical replicates were evaluated for both genders however we did not detect any reproducible differences in distribution of WISH signal between genders. Images of all WISH samples with detectable pelvic ganglia expression have been posted to the GUDMAP consortium database for public access (www.gudmap.org).

To begin to categorize gene expression patterns among the total 155 identified within the pelvic ganglia, we noted those genes that were expressed not only in pelvic ganglia but also in LUT epithelium (Table 2). Representative images of expression patterns observed for genes exhibiting both pelvic ganglia and LUT epithelial expression including Hand1, Satb1, Sox2, Gata3, Lmo1, and Trim9 are shown in Figure 4. Hand1, Satb1, Lmo1, and Trim9 were expressed at high levels in pelvic ganglia and discrete domains within medial urethral structures of the ejaculatory duct in males or lower vagina in females. Sox 2 and Gata3 exhibited much lower expression in pelvic ganglia with significantly stronger expression in urethral epithelium.

A second category of potential regulatory genes expressed in pelvic ganglia also exhibited expression in LUT mesenchyme (Table 3). Some of these genes exhibited strong pelvic ganglia expression accompanied by more modest expression in discrete urethral domains (Figure 5). Specifically Tacc2 and Sqstm1 exhibited diffuse regional expression in the ventral urethra at $15.5 \mathrm{dpc}$. Other genes, like the TF Gata2, exhibited strong regional expression throughout the upper third of the urethra including the pelvic ganglia. A few genes, such as Epas1, exhibited distinctive expression throughout the entire urethra, bladder neck, and pelvic ganglia. Whether these regional expression patterns are involved in dorsal-ventral patterning, development of vasculature or muscle remains to be determined through co-localization with cell-type specific markers and evaluation of mutant alleles that are being constructed (Harding et al., 2011; Skarnes et al., 2011).

During imaging and analysis of fetal WISH samples, we observed that several genes exhibited expression confined to distinct regional domains within and around the pelvic ganglia. Rtn4, Ndrg2, Gata2, and Ndrg4 illustrate such restricted patterns (Figure 6). Gata2 probes detected expression at very high levels in a banded pattern throughout the bladder neck and upper urethra
Table 1 | Genes detected in pelvic ganglia at $15.5 \mathrm{dpc}$ by whole-mount in situ hybridization.

\begin{tabular}{|c|c|c|c|c|c|}
\hline $\begin{array}{l}\text { Gene } \\
\text { name }\end{array}$ & $\begin{array}{l}\text { Probe } \\
\text { no. }\end{array}$ & $\begin{array}{l}\text { Gene } \\
\text { name }\end{array}$ & $\begin{array}{l}\text { Probe } \\
\text { no. }\end{array}$ & $\begin{array}{l}\text { Gene } \\
\text { name }\end{array}$ & $\begin{array}{l}\text { Probe } \\
\text { no. }\end{array}$ \\
\hline 4930555K19Rik & MTF1122 & Kbtbd5 & MTF1668 & Rnf187 & MTF1390 \\
\hline Ablim1 & MTF1346 & $K d m 4 a$ & MTF1428 & Rnf41 & MTF1048 \\
\hline${ }^{*} A h r$ & MTF1011 & ${ }^{*} K d m 4 b$ & MTF1420 & ${ }^{*} R n f 44$ & MTF1049 \\
\hline Aip & MTF0733 & ${ }^{*} K d m 5 b$ & MTF1089 & Rorc & MTF0058 \\
\hline Ankfy 1 & MTF1529 & Kif1a & MTF1178 & ${ }^{*} R \operatorname{tn} 2$ & MTF0682 \\
\hline${ }^{*}$ Atf2 & MTF0755 & Kif1b & MTF1179 & Rtn4 & MTF0684 \\
\hline${ }^{*}$ Atf4 & MTF0756 & ${ }^{*} K I f 7$ & MTF0931 & Satb1 & MTF0706 \\
\hline${ }^{*}$ Atf5 & MTF0785 & KIh/9 & MTF1553 & ${ }^{*} S f 1$ & MTF0869 \\
\hline * Bach2 & MTF0582 & *Lass5 & MTF1983 & $\sin 3 b$ & MTF1846 \\
\hline Bop1 & MTF0947 & Lcor & MTF1923 & ${ }^{*} \operatorname{Six} 1$ & MTF0180 \\
\hline Brca1 & MTF1518 & Limk1 & MTF1451 & * Smad9 & MTF2019 \\
\hline Brd2 & MTF0221 & ${ }^{*} \operatorname{Lmo} 1$ & MTF0178 & Smarca4 & MTF0639 \\
\hline Brd9 & MTF1959 & Lztr1 & MTF0783 & ${ }^{*}$ Smarcd 1 & MTF0643 \\
\hline $\mathrm{Cbl}$ & MTF1556 & ${ }^{*}$ Maff & MTF0555 & Snf8 & MTF1173 \\
\hline Chd4 & MTF1557 & ${ }^{*}$ Mafg & MTF0556 & ${ }^{*}$ Sox 10 & MTF0511 \\
\hline${ }^{*}$ Cited 2 & MTF1133 & Mkrn2 & MTF0891 & ${ }^{*}$ Sox2 & MTF0503 \\
\hline Cnot7 & MTF1158 & MIlt4 & MTF1184 & ${ }^{*}$ Sox 4 & MTF0505 \\
\hline Cops3 & MTF1309 & ${ }^{*} M n t$ & MTF1193 & ${ }^{*}$ Sox9 & MTF0510 \\
\hline Cops6 & MTF1155 & Mpnd & MTF1149 & ${ }^{*}$ Sqstm 1 & MTF0693 \\
\hline Crip2 & MTF1826 & Mrps17 & MTF1490 & Srebf2 & MTF1206 \\
\hline Cttn & MTF0994 & ${ }^{*} M x d 1$ & MTF0799 & ${ }^{*}$ Stat3 & MTF0773 \\
\hline${ }^{*}$ Cux2 & MTF0744 & ${ }^{*} M y c$ & MTF1817 & ${ }^{*}$ Tacc2 & MTF0635 \\
\hline Dcun1d3 & MTF1816 & ${ }^{*}$ Myt1 & MTF0902 & Tbx3 & MTF1311 \\
\hline${ }^{*}$ Dido 1 & MTF1296 & ${ }^{*} M y t 11$ & MTF0907 & ${ }^{*} T c f 4$ & MTF1939 \\
\hline${ }^{*} D p f 1$ & MTF1376 & ${ }^{*}$ Ncoa2 & MTF0618 & ${ }^{*} T c f a p 2 b$ & MTF0778 \\
\hline${ }^{*}$ Dpf2 & MTF1298 & Ndrg1 & MTF0964 & ${ }^{*}$ Tead 1 & MTF0596 \\
\hline Dpf3 & MTF1503 & Ndrg2 & MTF0967 & ${ }^{*}$ Thbs3 & MTF1516 \\
\hline${ }^{*} E 4 f 1$ & MTF0923 & Ndrg3 & MTF0970 & Tomm6 & MTF0164 \\
\hline Eea1 & MTF1538 & Ndrg4 & MTF0968 & Trim16 & MTF1065 \\
\hline Eif4h & MTF1933 & ${ }^{*} \mathrm{Nfe} 2 / 1$ & MTF0573 & Trim2 & MTF1098 \\
\hline${ }^{*} E t s 2$ & MTF0400 & $N r 2 f 1$ & MTF0077 & Trim3 & MTF1056 \\
\hline${ }^{*}$ FoS & MTF0567 & ${ }^{*} \mathrm{Nr} 4 \mathrm{a} 1$ & MTF0050 & Trim47 & MTF1426 \\
\hline${ }^{*}$ Foxk2 & MTF1899 & ${ }^{*}$ Onecut1 & MTF0151 & Trim68 & MTF1697 \\
\hline${ }^{*}$ Gata2 & MTF0805 & ${ }^{*}$ Otp & MTF0191 & Trim8 & MTF1060 \\
\hline * Gata3 & MTF0806 & ${ }^{*}$ Pax3 & MTF0265 & Trim9 & MTF1396 \\
\hline${ }^{*}$ Gtf2a 1 & MTF1956 & Pcgf1 & MTF1700 & Usf1 & MTF0830 \\
\hline${ }^{*}$ Gtf3a & MTF1861 & ${ }^{*}$ Pcgf3 & MTF1023 & ${ }^{*}$ Usf2 & MTF0831 \\
\hline${ }^{*}$ Hand 1 & MTF0823 & ${ }^{*} P h f 1$ & MTF1283 & ${ }^{*} V p s 26 b$ & MTF1493 \\
\hline${ }^{*}$ Hand2 & MTF0972 & Phip & MTF0241 & Zbtb16 & MTF1759 \\
\hline${ }^{*} \mathrm{Heyl}$ & MTF0955 & ${ }^{*}$ Phox $2 b$ & MTF0363 & Zbtb22 & MTF1769 \\
\hline * Hivep2 & MTF0689 & Plxna3 & MTF1335 & ${ }^{*}$ Zcchc14 & MTF1545 \\
\hline${ }^{*} \mathrm{Hmbox} 1$ & MTF1211 & Plxnc1 & MTF1329 & $Z f h \times 2$ & MTF1525 \\
\hline${ }^{*} \mathrm{Hmgxb3}$ & MTF2008 & Pogz & MTF1874 & ${ }^{*} Z$ fh $\times 3$ & MTF0141 \\
\hline${ }^{*} \mathrm{Hm} \times 1$ & MTF0006 & ${ }^{*}$ Pou $2 f 2$ & MTF0219 & *Zfp318 & MTF1770 \\
\hline${ }^{*}$ Hoxc10 & MTF0105 & ${ }^{*}$ Pou3f3 & MTF0210 & * Zfp326 & MTF1771 \\
\hline${ }^{*} \mathrm{Hoxc8}$ & MTF0319 & *Pou6f1 & MTF0215 & Zfp426 & MTF1369 \\
\hline${ }^{*}$ Hoxd 10 & MTF0106 & *Prox 1 & MTF0329 & ${ }^{*} Z f p 467$ & MTF0898 \\
\hline Hoxd3 & MTF0135 & ${ }^{*} \operatorname{Prrx} 1$ & MTF0196 & *Zfp612 & MTF1382 \\
\hline Ing4 & MTF1285 & ${ }^{*} R n f 112$ & MTF0870 & ${ }^{*}$ Zmynd8 & MTF1571 \\
\hline *Irf5 & MTF0560 & ${ }^{*} \operatorname{Rnf113a1}$ & MTF1052 & ${ }^{*} Z n r f 1$ & MTF1051 \\
\hline${ }^{*}|s| 1$ & MTF1380 & Rnf130 & MTF0900 & Zscan21 & MTF0908 \\
\hline un & MTF0551 & Rnf14 & MTF1033 & & \\
\hline
\end{tabular}


Table 2 | Genes detected in pelvic ganglia and LUT epithelium.

\begin{tabular}{|c|c|c|c|c|c|}
\hline $\begin{array}{l}\text { Gene } \\
\text { name }\end{array}$ & $\begin{array}{l}\text { Probe } \\
\text { no. }\end{array}$ & $\begin{array}{l}\text { Gene } \\
\text { name }\end{array}$ & $\begin{array}{l}\text { Probe } \\
\text { no. }\end{array}$ & $\begin{array}{l}\text { Gene } \\
\text { name }\end{array}$ & $\begin{array}{l}\text { Probe } \\
\text { no. }\end{array}$ \\
\hline 4930555k19Rik & MTF1122 & Hox & MTF0319 & $3 a 1$ & 1052 \\
\hline Ablim1 & MTF1346 & HoxD3 & MTF & Rnf130 & MTF0900 \\
\hline Ahr & MTF1011 & $\operatorname{lrf5}$ & MTF0560 & Satb1 & MTF0706 \\
\hline Atf5 & MTF0785 & Lmo1 & MTF0178 & Sox2 & MTF0503 \\
\hline Baz2a & MTF0233 & Mafg & MTF0556 & Sqstm1 & MTF0693 \\
\hline Dcun1d3 & MTF1816 & Lcor & MTF1923 & Thbs3 & MTF1516 \\
\hline Bop1 & MTF0947 & Myt1I & MTF0371 & Trim 16 & MTF1065 \\
\hline Cnot7 & MTF1158 & $N f e 2 L 1$ & MTF0573 & Trim2 & MTF1098 \\
\hline Dpf3 & MTF1503 & Pax3 & MTF0265 & Trim9 & MTF1396 \\
\hline Gata3 & MTF0806 & Phip & MTF0241 & Zbtb16 & MTF1759 \\
\hline Gtf3a & MTF1861 & Pou2f2 & MTF0219 & Zfp426 & MTF1369 \\
\hline Hand1 & MTF0823 & Rnf187 & MTF1390 & Zfp6339 & MTF1886 \\
\hline
\end{tabular}

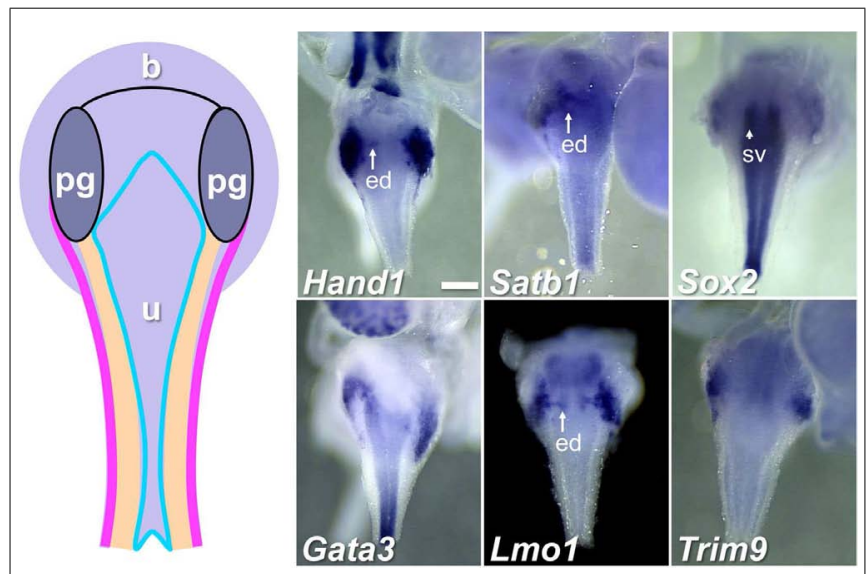

FIGURE 4 | Genes expressed in pelvic ganglia and urethral epithelium in the fetal mouse LUT. A schematic diagram of LUT represents dorsal views of the urethra $(u)$, including the epithelial layer (blue), mesenchymal layer (peach), muscular layer (pink), and pelvic ganglia (pg). Distinct expression patterns in the urethral epithelium and pelvic ganglia are evident in dorsal views at $15.5 \mathrm{dpc}$ for a subset of WISH samples surveyed. All images are $50 \times$ magnification with a $300 \mu \mathrm{m}$ scale bar in the first panel. ed, Ejaculatory duct (arrow); sv, seminal vescicles (arrowhead). Gene abbreviation/MGI gene ID/gender of sample: Hand1/103577/male; Satb 1/105084/male; Sox2/98364/female; Gata3/95663/male; Lmo1/102812/male; Trim9/2137354/female.

including the pelvic ganglia. This contrasted to very restricted expression observed for Rtn 4 and $N d r g 2$ within the pelvic ganglia. Ndrg4 exemplifies a subset of genes that showed very highly localized expression within clusters of cells internal to the pelvic ganglia in two oval domains that were either parallel to the axis of the bladder neck (horizontal) or vertically aligned to the urethral epithelium (vertical). Several other genes including Rnf31, Kiflb, and Mitc1 exhibited expression in these oval domains albeit at much lower levels than Ndrg4 (data not shown, WISH images posted to www.gupmap.org). Given that TFs play a prominent role in patterning the developing central nervous system, the regulatory factors identified here may play essential roles in specifying neuronal
Table 3 | Genes detected in pelvic ganglia and LUT mesenchyme.

\begin{tabular}{llllll}
\hline $\begin{array}{l}\text { Gene } \\
\text { name }\end{array}$ & $\begin{array}{l}\text { Probe } \\
\text { no. }\end{array}$ & $\begin{array}{l}\text { Gene } \\
\text { name }\end{array}$ & $\begin{array}{l}\text { Probe } \\
\text { no. }\end{array}$ & $\begin{array}{l}\text { Gene } \\
\text { name }\end{array}$ & $\begin{array}{l}\text { Probe } \\
\text { no. }\end{array}$ \\
\hline Aip & MTF0733 & Heyl & MTF0955 & Rtn4 & MTF0684 \\
Bach2 & MTF0582 & Hivep2 & MTF0689 & Smarcd1 & MTF0643 \\
Crip2 & MTF1826 & KIf7 & MTF0931 & Sqstm1 & MTF0693 \\
Cux2 & MTF0744 & Kdm4a & MTF1428 & Tacc2 & MTF0635 \\
Epas1 & MTF0540 & Meis1 & MTF0118 & Tead1 & MTF0596 \\
Fos & MTF0567 & Myc & MTF1817 & Usf1 & MTF0830 \\
Gata2 & MTF0805 & Ncoa2 & MTF0618 & Usf2 & MTF0831 \\
Gtf2a1 & MTF1956 & Ndrg2 & MTF0967 & Vps26b & MTF1493 \\
Hand2 & MTF0972 & Pcgf3 & MTF1023 & Zmym3 & MTF0879
\end{tabular}

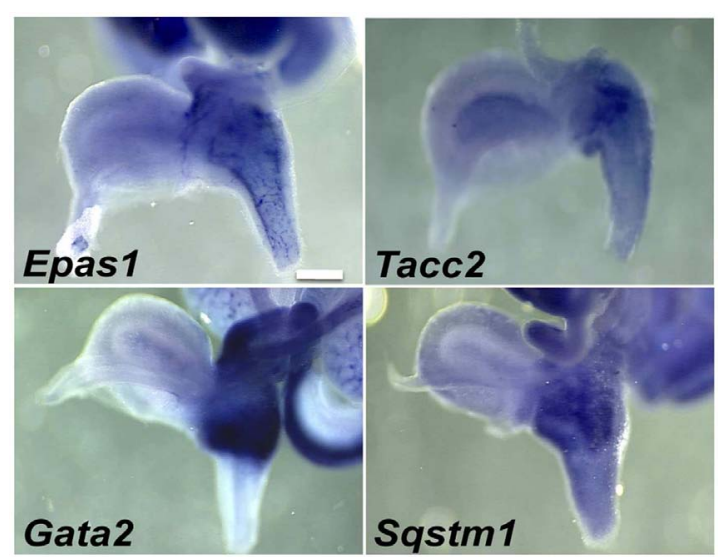

FIGURE 5 | Pelvic ganglia and urethral mesenchyme expression of genes in the fetal LUT identified by WISH. Lateral views of gene expression patterns detected for a subset of genes expressed in both pelvic ganglia and urethral mesenchyme. All images are 50x magnification with a $300 \mu \mathrm{m}$ scale bar. Gene abbreviation/MGI gene ID/gender of sample: Epas1/109169/female; Tacc2/1928899/male; Gata2/95662/female; Sqstm1/107931/female.

subtypes or may be required for the maintenance of different cell populations within the pelvic ganglia as this structure matures.

The tight clustering of cells labeled by Ndrg4 within a central domain in the developing pelvic ganglia is reminiscent of processes that occur in development of ciliary ganglia, sympathetic ganglia, and dorsal root ganglia. In these ganglia differentiating neurons and progenitors segregate into regional domains that are recognizable on the basis of markers that label differentiated neurons versus those that label progenitors (Muller and Rohrer, 2002; Callahan et al., 2008). In order to determine whether a similar segregation process might account for the localized expression of $\mathrm{Ndrg} 4$ and other TFs in the oval domains we observed in developing pelvic ganglia, we evaluated the distribution of Sox $10+$ and Phox $2 \mathrm{~b}+$ cells in LUT tissues of Sox10-H2BVenus, Phox 2b-H2BCFP double transgenic fetal mice. The Sox10-H2BVenus BAC transgenic line recapitulates expression patterns of the endogenous protein and thus labels NC-derived progenitors during development as well as peripheral glia in adult tissues (Corpening et al., 2011). Conversely the Phox $2 b$-H2BCFP BAC transgenic is up-regulated 


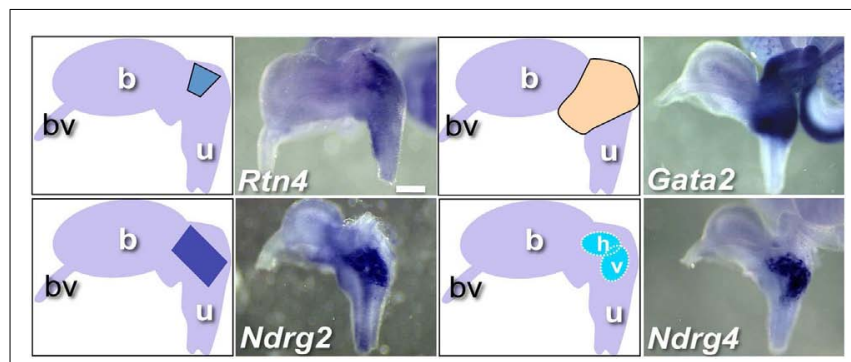

FIGURE 6 | WISH Gene expression patterns within and around fetal pelvic ganglia. Representative lateral views of individual gene expression patterns that exhibit distinct regional expression patterns within the pelvic ganglia are shown. Accompanying diagrams emphasize area of highest LUT expression detected for each gene. All images are $50 \times$ magnification with a $300 \mu \mathrm{m}$ scale bar. Gene abbreviation/MGI gene ID/gender of sample: Rtn4/1915835/male; Gata2/95662/female; Ndrg2/1352498/female; Ndrg4/2384590/female. (b, bladder; bv, blood vessel; $u$, urethra; $h$, horizontal domain; v, vertical domain). and maintained at high levels in peripheral neurons (Corpening et al., 2008). Concurrent IHC staining for PGP9.5 and $\mathrm{Hu}$ was applied to these samples to confirm the location of differentiating neurons since the distribution of Phox $2 \mathrm{~b}$ has previously not been examined at high resolution in the developing pelvic ganglia. Confocal images of sagittal sections through the LUT revealed the pelvic ganglia as a strongly PGP9.5/Hu+ triangular structure consistent with prior reports of the overall triangular shape of this ganglia in adult mice (Figure 7; Wanigasekara et al., 2003). While the majority of PGP9.5+ cells resided within the structure of the pelvic ganglia, a few PGP9.5+ cells were evident within the dorsal and ventral aspects of the bladder wall (Figure 7A). Interestingly, within the pelvic ganglia at $15.5 \mathrm{dpc}$ we observed noticeable oval domains strongly positive for Sox10-H2BVenus expression (Figure $7 \mathbf{A}^{\prime}$ ). Such domains were weakly Phox $2 b-\mathrm{H} 2 \mathrm{BCFP}+$, which would be consistent with progenitor cells, while nearby cells were strongly Phox2b-H2BCFP+, PGP9.5+, and $\mathrm{Hu}+$ consistent with neuronal identity (Figure 7B). The regional density of Sox10+ cells within oval domains was observed in multiple samples from Sox10-H2BVenus, Phox $2 b$-H2BCFP double transgenic embryos and appears to coincide with the regions labeled by WISH for Ndrg4 and other genes. The clustering of large numbers of strongly Sox $10+$ cells in the interior of the pelvic ganglia demonstrates that NC-derived progenitors are present in this region at $15.5 \mathrm{dpc}$ and further supports the notion that regional expression patterns observed in WISH are indicative of domains with the developing pelvic ganglia at this stage.

To confirm expression within pelvic ganglia and attempt to better define the distribution of individual gene transcripts within pelvic ganglia, sectional in situ hybridization (SISH) was performed (Figure 8). In addition, we evaluated public SISH data posted to Eurexpress for the distribution of these transcripts in the LUT (Diez-Roux et al., 2011). In sagittal tissue sections captured close to the mid-line, colorimetric ISH signal was present for Crip2, Ndrg2, Ndrg4, Satb1, and Sqstm1 in proximity to the nephric duct and ureter insertion sites where the bladder neck joins the urethra (Figure 8D). Gata2 expression was observed throughout

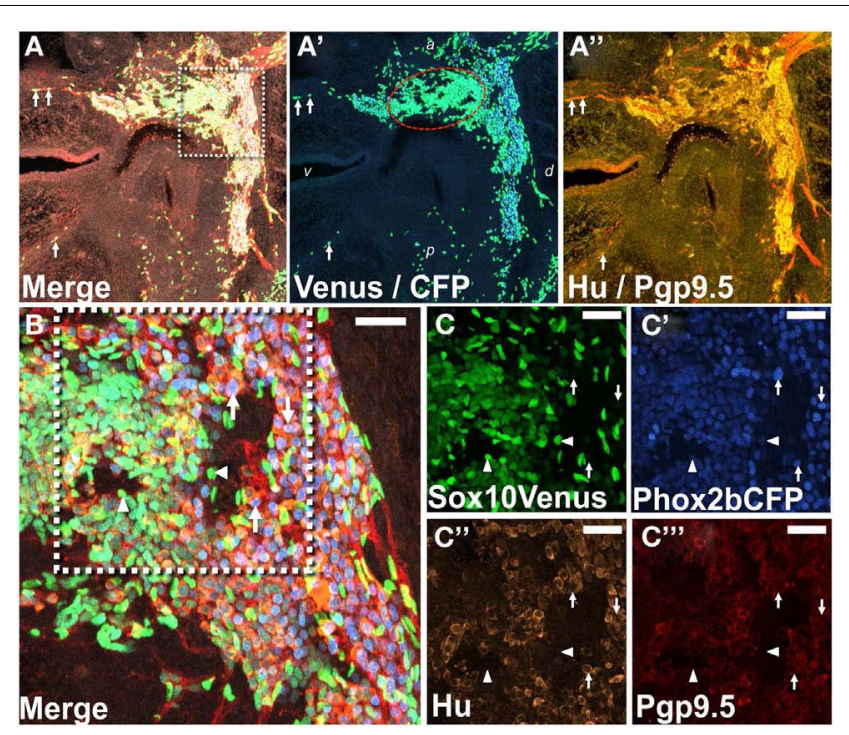

FIGURE 7 | Regional segregation of NC-derived progenitors and neurons within fetal pelvic ganglia. (A) Cryosection through the lateral sagittal plane of pelvic ganglia collected from Phox $2 b-\mathrm{H} 2 \mathrm{BCFP}$,

Sox10-H2BVenus double transgenic female fetal mouse stained for PGP9.5 and $\mathrm{Hu}$ shows the overall triangular shape of the pelvic ganglia at $15.5 \mathrm{dpc}$. Merged confocal image at $200 \times$ magnification captures nuclear Sox10-H2BVenus (green), nuclear Phox2b-H2BCFP (blue), cytoplasmic PGP9.5 (red), and Hu (gold). Differentiating neurons in the bladder wall identified by residual nuclear H2BVenus expression are co-labeled by up-regulation of cytoplasmic PGP9.5 (arrows). (A') Confocal image showing channels only for Venus and CFP from the cryosection presented in (A) is shown. An oval domain comprised of densely packed Sox10+ cells (green nuclei, encircled by red dotted line) is evident with Phox $2 b+$ neurons (blue nuclei) being most numerous outside this region. ( $\mathbf{A}^{\prime \prime}$ ) A confocal image shows channels for PGP9.5 and Hu from the cryosection presented in (A) PGP9.5 (red) labels numerous cell bodies at the dorsal aspect of the pelvic ganglia, a small area of differentiating neurons nearest the anterior bladder neck, and extrinsic nerve fibers entering the ganglia. Hu (gold) labels numerous cell bodies with the greatest density being around the perimeter of the pelvic ganglia. (B) Higher magnification confocal image $(400 \times)$ from the boxed region in (A) shows high density of $\mathrm{H} 2 \mathrm{BV}$ enus+ progenitors in the core of the oval progenitor domain with Phox2b+, PGP9.5+, Hu+ neurons clustered at the dorsal aspect of the pelvic ganglia. Single confocal channels at $630 \times$ magnification from boxed area in (B) are shown for Sox10-H2BVenus [(C), green], Phox2b-H2BCFP [(C'), blue], Hu+ neuronal

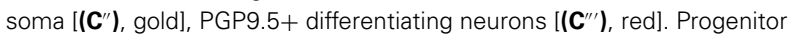
cells labeled by H2BVenus nuclear fluorescence (arrowheads) exhibit low or no expression of Phox $2 b-\mathrm{H} 2 \mathrm{BCFP}$ and no expression of PGP9.5 and Hu. Differentiating neurons lack $\mathrm{H} 2 \mathrm{BV}$ enus label, exhibit bright Phox $2 b-\mathrm{H} 2 \mathrm{BCFP}$ nuclear fluorescence as well as cytoplasmic Hu and PGP9.5 labeling (arrows). Dorsal (d), ventral (v), anterior (a), and posterior ( $p$ ) orientations are indicated on $\left(\mathbf{A}^{\prime}\right)$. Scale bar: $25 \mu \mathrm{m}$.

the entire area of the bladder neck and was not restricted to pelvic ganglia. Expression of Ndrg2, Ndrg4, Klf7, Lmo1, Rtn2, and Rtn4 was present not only at high levels in the pelvic ganglia (Figure 8D) but also in other aspects of the developing nervous system (data not shown, public images accessible at www.eurexpress.org). Crip2 signal was observed in a diffuse punctate distribution within the pelvic ganglia but was also present in other tissues nearby. The expression patterns detected by SISH are consistent with expression of these genes within pelvic ganglia. 


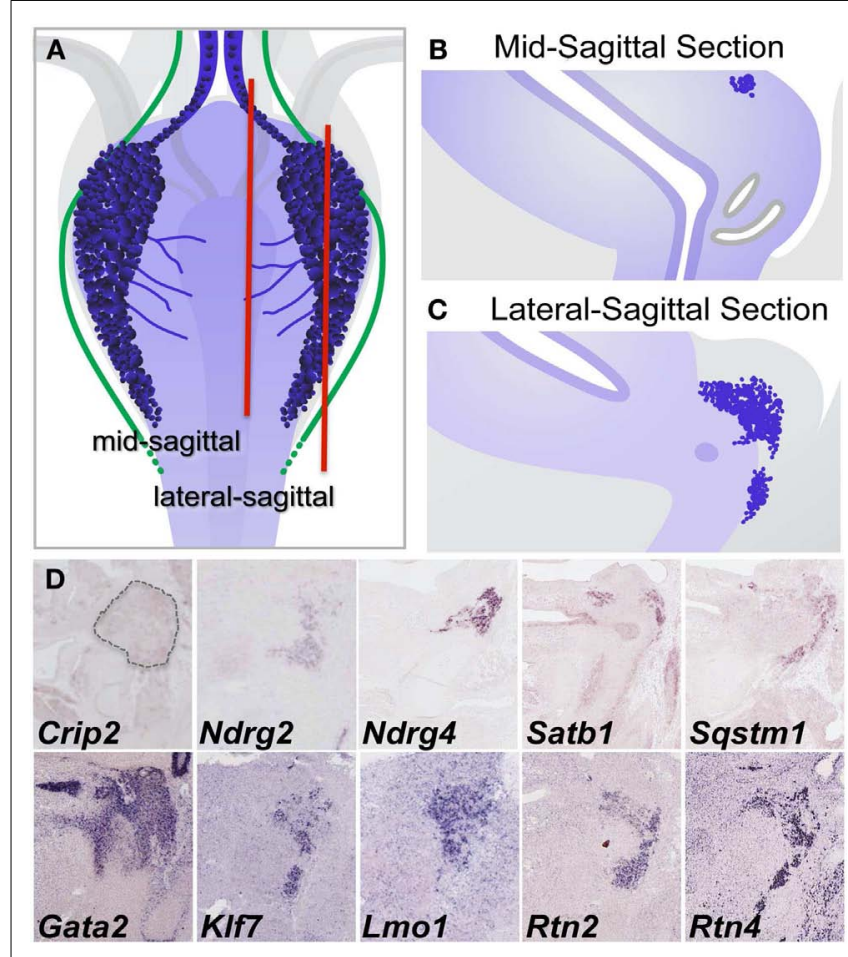

FIGURE 8 | Validation of gene expression patterns in pelvic ganglia by sectional in situ hybridization (SISH). (A) Schematic diagram of $15.5 \mathrm{dpc}$ fetal mouse LUT viewed dorsally illustrates pelvic ganglia (dark blue clusters), neurites extending from pelvic ganglia across the dorsal urethral surface (blue lines), and axonal processes (green lines) relative to LUT structures. Red vertical lines indicate the relative planes of cryosections taken through mid-sagittal (B) and lateral sagittal regions (C) for SISH processing. Colorometric micrographs of SISH signals obtained in cryosections for individual genes (D). Images for Crip2, Ndrg4, Satb1, and Sqstm 1 are from data deposited at the GUDMAP database (probe IDs: MGI:3507380, MGI:3506573, MGI:3506384, MGI:3506375, respectively). Images for Ndrg2, Gata2, Klf7, Lmo1, Rtn2, and Rtn4 derive from data posted on Eurexpress.org (probe IDs: euxassay_010581, section 14; euxassay_018037, section 14; euxassay_003485, section 16; euxassay_017874, section 07; euxassay_018264, section 14; and euxassay_004344, section 14, respectively). Dotted line outlines the pelvic ganglia border in SISH panel for Crip2 as the expression for this gene is not homogeneous within cells but was observed as faint punctate signal within some cells and not in others.

\section{ANALYSIS OF GENE EXPRESSION IN POST-NATAL PELVIC GANGLIA}

Multiple TFs are essential for patterning distinct regions of the central nervous system (Sham et al., 1993; Barrow et al., 2000; Tomotsune et al., 2000; Kitaguchi et al., 2001) and for initiating and maintaining neurogenesis in the adult CNS (Gao et al., 2011; Jacquet et al., 2011; Karalay et al., 2011; Li et al., 2011). The gene expression patterns we observed in fetal LUT at $15.5 \mathrm{dpc}$ could represent transient transcription needed during development but might also be necessary for maintenance of neuronal and glial lineages as the LUT matures. To evaluate this possibility, we examined temporal expression for a subset of genes identified in the initial WISH screen. Pelvic ganglia were visualized by whole-mount fluorescence imaging of Sox10-H2BVenus transgene expression. Fluorescence expressed from the Sox $10-\mathrm{H} 2 \mathrm{BVenus}$ transgene facilitates collection of pelvic ganglia and avoids surrounding tissues. Pelvic ganglia were imaged and dissected at five discrete stages [14.5 and 15.5dpc, Post-natal day 2 (P2), P10, and P21] and total RNA was isolated for analysis by RT-PCR. At all stages the pelvic ganglia were strongly labeled by Sox10-H2BVenus expression, which provided a perspective of the size and position of the pelvic ganglia relative to the bladder at multiple stages (Figures 9A-C). At 14.5dpc the pelvic ganglia are elongated clusters that flank the bladder neck and extend more than half way down either side of the pelvic urethra. During post-natal maturation these ganglia condense into the better-known triangular shape that is smaller compared to the overall size of the mature bladder.

To determine whether genes detected in the initial WISH screen maintained their expression at multiple points in pelvic ganglia ontogeny, RT-PCR was implemented using both RNA from intact LUT and from dissected pelvic ganglia. To ensure specificity of the RT-PCR assays oligonucleotide primers were designed to extend from $3^{\prime}$ untranslated regions into adjacent exons so that amplification from genomic DNA was avoided. In addition, primers were positioned to avoid homologous regions between related gene family members (Table S2 in Supplementary Material). The assays used only produced PCR products from cDNA with the exception of Sox2, which lacks introns (Figure 9). These gene-specific primers were used for RT and PCR detection of individual transcripts in pelvic ganglia RNA isolates at each of five stages. Control samples run in parallel consisted of $15.5 \mathrm{dpc}$ intact LUT RNA that included distal ureter, bladder, pelvic ganglia, urethra, and genital tubercle as well as genomic DNA (Figure 9D). All RT-PCR samples for an individual gene were reverse transcribed and PCR amplified in parallel then evaluated by gel electrophoresis to confirm appropriate product size. All of the genes initially detected by in situ hybridization were also detected by RT-PCR at $15.5 \mathrm{dpc}$ in multiple biological and technical replicates. While the majority of genes examined produced robust RT-PCR product, Pax3 was not detected at $14.5 \mathrm{dpc}$ and product for this gene was barely discernable at $15.5 \mathrm{dpc}$ consistent with the extremely low WISH signal. Pax3 RT-PCR product was still present at P10 but was no longer detectable at $\mathrm{P} 21$. The other genes evaluated were detected at all the stages examined, although the intensity of bands obtained for Gata2, Gata3, and Phox $2 b$ suggests that these factors diminish by P21. Intensity of RT-PCR product also varied noticeably for Hand2. While this could be due to variations in input cDNA between samples, previous temporal studies of Hand2 expression in the enteric nervous system have shown that levels of this factor peak at $14.5 \mathrm{dpc}$ during fetal neurogenesis (D'Autreaux et al., 2007). The confirmed expression of these regulatory genes and their maintenance over a significant time frame in fetal development and post-natal maturation of pelvic ganglia leads to obvious questions about their functions in this structure.

\section{DISCUSSION}

It is widely accepted that sacral autonomic ganglia in the LUT derive from progenitors that originate at the $\mathrm{NC}$ and migrate into the region of the cloaca during organogenesis to form the pelvic ganglia. However the processes that control development of sacral autonomic ganglia and innervation of the LUT have not been described to date. Identification of genes that participate in this 


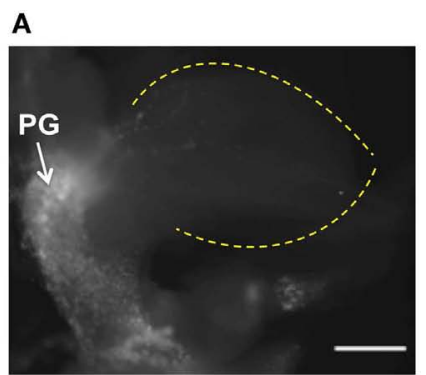

$14.5 \mathrm{dpc}$ whole-mount

C

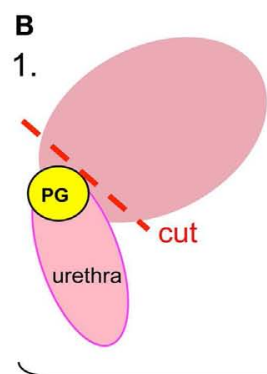

2.

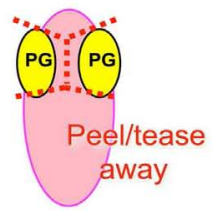

3.

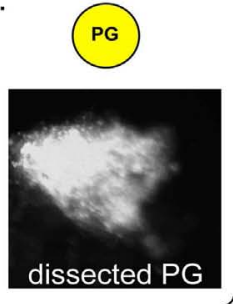

Process of sub-dissection

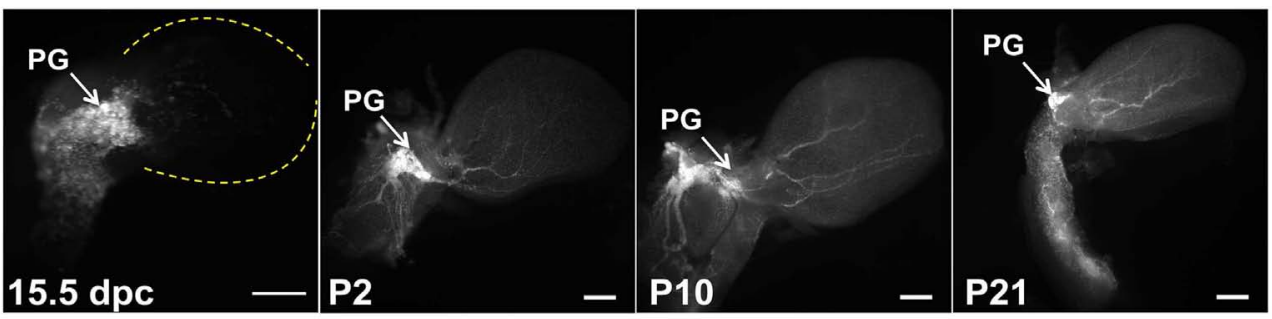

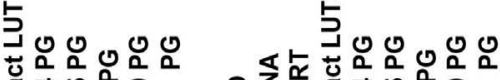

5

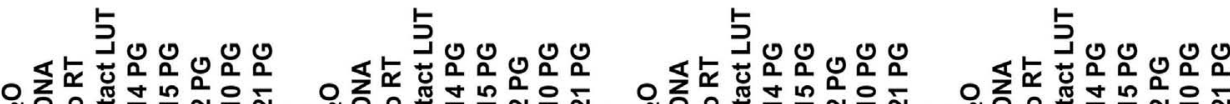

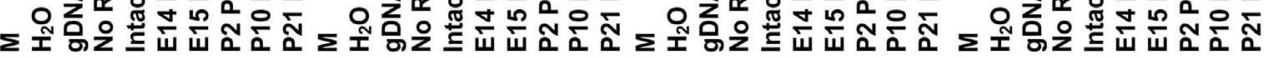
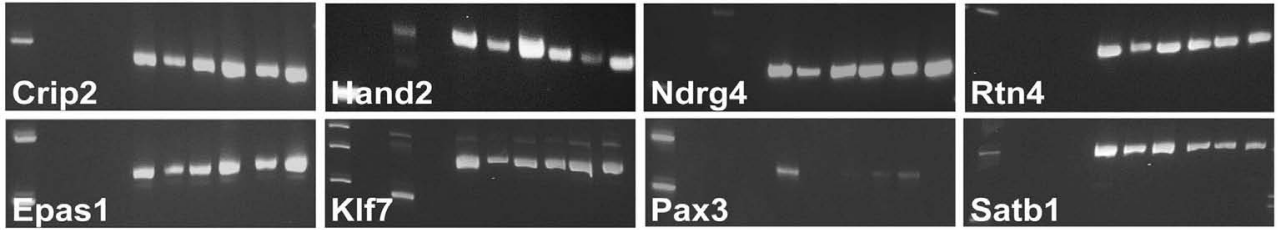

$\operatorname{Rtn} 4$
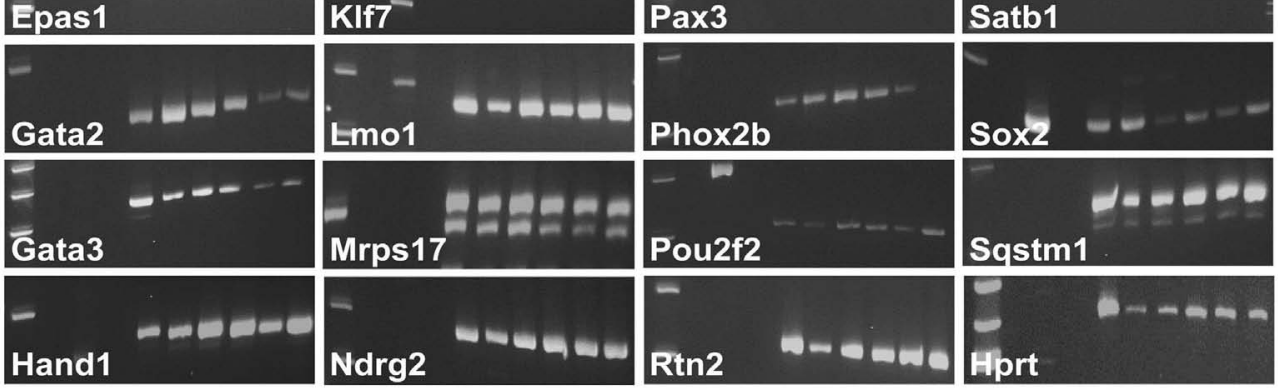

FIGURE 9 | Identification of genes that maintain expression in pelvic ganglia across multiple developmental stages. (A) NC derivatives labeled by Sox10 expression are evident in pelvic ganglia, bladder wall, and urethra of a Sox 10-H2BVenus transgenic embryo viewed laterally at 14.5dpc. (B) Schematic diagram illustrating the dissection technique to harvest pelvic ganglia based on Sox10-H2BVenus transgene fluorescence. (C) Relative size, shape, and position of pelvic ganglia compared to the overall bladder morphology are illuminated by Sox $10-\mathrm{H} 2 \mathrm{BV}$ enus expression in lateral images of 15.5dpc, P2, P10, P21 lower urinary tracts. Scale

bar $=1000 \mu \mathrm{m}$. (D) Gel electrophoresis images of RT-PCR products relative to a standard molecular weight marker identifies individual genes expressed in fetal development and post-natal maturation of pelvic ganglia. Sample order: no template water control, genomic DNA control, no RT control (15.5dpc RNA sample), 15.5dpc intact LUT (consisting of distal ureter, bladder, urethra, pelvic ganglia, and genital tubercle) and Sox 10-H2BVenus pelvic ganglia RNA isolates harvested at $14.5 \mathrm{dpc}$, $15.5 \mathrm{dpc}, \mathrm{P} 2, \mathrm{P} 10$, and P21. A housekeeping control gene (Hprt) is included for comparison.

process is one means to gain an entry point into developmental pathways that will not only provide baseline information for future interrogation of gene function but may lead to discovery of relevant disease genes. In this report we have identified 155 murine genes that exhibit expression in pelvic ganglia including 88 TFs of which 82 have not been previously been linked to pelvic ganglia. Regional differences in expression patterns of these factors within the pelvic ganglia suggest progenitors and differentiating neurons are regionally segregated in early stages of development. Temporal analysis of expression for a subset of these genes demonstrates that many maintain their expression from early fetal organogenesis of the LUT through to post-natal maturation of pelvic ganglia. Given the clear role played by TFs in induction and patterning of the central nervous system as well as recent studies that demonstrate TFs play an essential part in determining cell fate decisions (Collombat et al., 2003; Hang and Stein, 2011; Hu He et al., 2011; Liu et al., 
2011; Pan and Wright, 2011), the genes identified here should be prioritized for future studies of sacral innervation.

As a platform for annotating gene expression in the LUT, we provide an initial spatial distribution of neural elements in the fetal mouse LUT based on IHC and histochemical staining at $15.5 \mathrm{dpc}$. Our identification of large numbers of PGP9.5+ cells visible as a dense network of neural fibers present in the developing bladder wall suggests that neural connections are being made during expansion and maturation of the bladder wall. Moreover the marked difference between cell numbers labeled by PGP9.5 immunoreactivity and axonal projections labeled by VAChT histochemistry suggests that a large number of PGP9.5+ cells are not cholinergic. This result raises several interesting questions: What cell types derive from the PGP9.5+ cells present in the medial wall and bladder dome at $15.5 \mathrm{dpc}$ ? Is the broad PGP9.5+ expression representative of other previously unrecognized neuronal lineages at this stage of development given the documented role for PGP9.5 in neuronal development and synaptic connectivity (Sakurai et al., 2006; Cartier et al., 2009)? What are the relationships between VAChT + axonal processes and the PGP9.5+ cells in the bladder wall if any? We also observed PGP9.5+ neuronal cell bodies in the bladder wall by sectional analysis at $15.5 \mathrm{dpc}$ (Figure 7 ). In the adult mouse neuronal soma have not previously been reported in the detrusor (Yan and Keast, 2008), but intramural ganglia are present in rats at $\mathrm{P} 0$ that then decline in numbers postnatally (Iuchi et al., 1994; Alian and Gabella, 1996; Zvarova and Vizzard, 2005). Whether derivatives of the early PGP9.5+ cells we have observed survive in the adult bladder and what connections they have with other cell types remains to be determined. These questions await future analyses of discrete lineages in a comprehensive timeline of the developing bladder wall.

Sox10 expression marks multi-potent NC-derived progenitors in early stages of development and is maintained in glia as peripheral ganglia mature (Bremer et al., 2011). In this study we demonstrate that Sox10 expression is present in a large number of cells in the LUT at $15.5 \mathrm{dpc}$. The expression pattern observed was detected with an in situ probe that contained homology to other SoxE box proteins including Sox 8 and Sox9. However, it is unlikely that any of the Sox10 WISH signal is due to cross-hybridization to other Sox gene family members because riboprobes are capable of discriminating between gene family members when RNase treatment is performed after hybridization to degrade any mismatched hybrid strands as was done in this case. Neither Sox 8 nor Sox9 probes exhibited intense staining of pelvic ganglia or any signal throughout the urethra comparable to what was observed for the Sox10 WISH probe. In addition, the expression pattern we document for the Sox 10-H2BVenus transgene in LUT (Figure 8) is comparable to the Sox 10 WISH probe signal and thus supports the specificity of the WISH signal detected. Surprisingly few studies have previously visualized NC-derived progenitors in the developing murine LUT (Stewart et al., 2008; Abler et al., 2011; Mundell et al., 2012). Given the large numbers of NC-derived Sox10+ cells in the LUT, studies to investigate the lineages that derive from these progenitors and their inductive effects in this organ system should be of interest to the urologic community, particularly in light of bladder dysfunction in neurocristopathies like Spina bifida.
Prior to the presented analysis, few studies describing expression of TFs in pelvic ganglia had been published. Our survey identified a large number of potential TFs expressed in pelvic ganglia at $15.5 \mathrm{dpc}$. If a strict requirement for DNA-binding is imposed on this subset the list narrows to 88 TFs. Similar surveys to investigate glial-specific TFs in the developing central nervous system have also identified large numbers of genes in developing glia. Given the potential complexity of neuronal and glial cell types in adult pelvic ganglia identification of a large number of potential regulatory TFs at a single stage in development is not surprising. This entry-level screen provides a significantly expanded candidate list of genes that may now be pursued in functional studies to determine if these genes are required for maintaining neural progenitors, for promoting terminal differentiation of neurons, or for balancing segregation of lineages.

One conclusion from our study is that gene expression within the developing pelvic ganglia is not homogeneous. We documented expression patterns that appear to label a subset of cells within the pelvic ganglia at $15.5 \mathrm{dpc}$. Some of these subpopulations are labeled by TF expression (Hand1, Gata2, and Lmo1) but others (Rtn4, Ndrg2, and Ndrg4) have not proven to be TFs and were simply included in the initial survey based on the presence of predicted DNA-binding domain in their protein sequence (Gray et al., 2004). Despite not exhibiting DNA-binding activity, Rtn4, Ndrg2, and $N d r g 4$ are of particular interest because of their highly localized expression in pelvic ganglia and also because of their known roles in other aspects of neural development. The Rtn4 locus encodes Nogo, a major myelin-derived axon growth inhibitor that plays a role in axonal fasciculation and is also expressed on growing axons during development (Hunt et al., 2002). Ndrg2 encodes a member of the N-myc downstream-regulated gene (NDRG) family, is expressed in differentiating astroglial cells in the CNS and appears to play a role in astroglial activation (Shen et al., 2008; Takeichi et al., 2011). Perhaps the most remarkable expression pattern we describe is that of Ndrg4 that labels core clusters of cells within the developing pelvic ganglia. LUT phenotypes for Ndrg4 knockout mice have not been reported but these mutants do exhibit cognitive deficits and they are less tolerant of ischemic stress after cerebral infarction (Yamamoto et al., 2011). Whether TF or not, the expression patterns of these genes suggests regional domains within pelvic ganglia that have not previously been described.

Interestingly the distribution of Sox 10 and Phox $2 \mathrm{~b}$ relative to neuronal markers PGP9.5 and Hu also supports the tenant that the pelvic ganglia contains subdomains of progenitor cells and developing neurons. Both WISH and transgene expression indicate that Sox10 expression labels the largest total area of pelvic ganglia. However sectional analysis revealed that the highest density of Sox $10+$ progenitors, identified by H2BVenus nuclear transgene label, resides in an oval domain perpendicular to the urethra. Differentiating neurons labeled by Phox2b, PGP9.5, and $\mathrm{Hu}$ are clustered in greatest numbers outside this domain of high-density Sox10+ progenitors. Similar segregation of progenitors and differentiating neurons has previously been observed in sympathetic ganglia, ciliary ganglia, and dorsal root ganglia, all of which derive from NC-progenitors (Muller and Rohrer, 2002; Callahan et al., 2008; Tsarovina et al., 2008; Nishi et al., 2010). Identification of a progenitor domain within the developing pelvic ganglia is not 
entirely unexpected particularly given gene expression patterns in ciliary ganglia where neurons initially appear on the perimeter of an undifferentiated core in the developing ganglia (Muller and Rohrer, 2002). As development proceeds expression of neuronal markers becomes more uniform across the ciliary ganglia (Muller and Rohrer, 2002). Similar restructuring of the pelvic ganglia through development may occur as well. An expression profile of the TFs identified in this study relative to the regional placement of progenitors and neurons within the pelvic ganglia may identify factors that control this process. Initial studies that visualized calcium transients during development of sympathetic ganglia suggest that calcium signaling is somehow involved in the regional segregation of progenitors and neurons (McKinney and Kulesa, 2011).

While our survey has identified transcription of numerous potential regulatory factors based on in situ and RT-PCR, it is possible that the presence of mRNA does not necessarily imply protein expression due to post-transcriptional regulatory mechanisms that may be in place. Transcription of other TFs, like Tcf4 and Olig1 that function in gliogenesis, is known to occur several days in advance of protein expression (Lu et al., 2000; Fu et al., 2009). Definitive correlation between transcription and protein expression will require close attention to the specificity of any antibodies that are deployed for such studies as cross-reactivity between DNA-binding domains of TFs can complicate specific detection of closely related gene family members.

In summary, we have screened an extensive expression resource to identify potential regulatory genes that are expressed in the pelvic ganglia. This is the first comprehensive survey to identify genes that participate in development of LUT innervation. Our efforts have identified 82 genes that have not previously been identified in fetal mouse pelvic ganglia and demonstrate that some of these are maintained in the post-natal ganglia. Several of these genes exhibited expression in recognizable domains within the pelvic ganglia suggesting that there may be regional segregation of cell types within this structure. Future studies to identify those genes expressed in progenitors relative to differentiating neurons will be of interest for investigators seeking to better understand development of sacral innervation. Moreover, overlapping expression of individual TFs may impart neuronal identity analogous to domain specific expression conferred by TFs expressed in the spinal cord. Identifying the factors, whether TF or not, that control development and maintenance of pelvic ganglia is relevant for

\section{REFERENCES}

Abler, L. L., Keil, K. P., Mehta, V., Joshi, P. S., Schmitz, C. T., and Vezina, C. M. (2011). A high-resolution molecular atlas of the fetal mouse lower urogenital tract. Dev. Dyn. 240, 2364-2377.

Alian, M., and Gabella, G. (1996). Decrease and disappearance of intramural neurons in the rat bladder during post-natal development. Neurosci. Lett. 218, 103-106.

Aquino, J. B., Hjerling-Leffler, J., Koltzenburg, M., Edlund, T., Villar,

understanding bladder control and may benefit efforts to innervate artificial bladder scaffolds or repair damaged pelvic innervation.

\section{ACKNOWLEDGMENTS}

The authors thank Kevin Weller, David Flaherty, and Brittany Matlock for support in the Flow Cytometry Shared Resource at Vanderbilt University, Stephanie Skelton and Dennis Buehler for assistance with RNA preparation, and Jean-Marc DeKeyser for AChE staining. We appreciate the assistance of Susan Lloyd-MacGilp in the GUDMAP Editorial Office with submission of annotated image files. The VUMC Flow Cytometry Shared Resource is supported by the Vanderbilt Ingram Cancer Center (P30 CA68485) and the Vanderbilt Digestive Disease Research Center (P30 DK058404). Confocal imaging was performed through the use of the VUMC Cell Imaging Shared Resource, which is supported by NIH grants CA68485, DK20593, P30DK058404, HD15052, DK59637, and EY08126. The 2H3 Neurofilament antibody developed by T. M. Jessell and J. Dodd was obtained from the Developmental Studies Hybridoma Bank developed by the NICHD and maintained by The University of Iowa, Department of Biological Sciences. Work in EMS's laboratory was supported by funding from US National Institutes of Health grants DK070219 (subcontract), R01-DK078158, and RC1DK086594. Work in APM's laboratory was supported by a grant from the National Institutes of Health (DK 070181). Work in MHL's laboratory was supported a grant from the National Institutes of Health (DK070136). M. L. is a Principal Research Fellow of the National Health and Medical Research Council of Australia.

\section{SUPPLEMENTARY MATERIAL}

The Supplementary Material for this article can be found online at: http://www.frontiersin.org/Autonomic_Neuroscience/10.3389/ fnins.2012.00130/abstract

Table S1 | Compilation of WISH samples scored for gene expression in pelvic ganglia. A summary list of WISH samples surveyed that exhibited either definitive expression, potential expression (very weak), or clearly not detected in pelvic ganglia of mouse fetal LUT is provided. The gene symbol, MTF number, gene description, MGI gene ID, Ensembl gene ID, and MGI probe ID is listed for each sample viewed and scored. Transcription factor genes are indicated in column G.

Table S2 | RT-PCR primers utilized for each gene in the RT-PCR analysis.

Kranc, K. R., Farza, H., Henderson, D. J., Hurst, H. C., and Bhattacharya, S. (2001). Cardiac malformations, adrenal agenesis, neural crest defects and exencephaly in mice lacking Cited2, a new Tfap2 co-activator. Nat. Genet. 29, 469-474.

Barrow, J. R., Stadler, H. S., and Capecchi, M. R. (2000). Roles of Hoxal and Hoxa2 in patterning the early hindbrain of the mouse. Development 127, 933-944.

Bella, A. J., Lin, G., Garcia, M. M., Tantiwongse, K., Brant, W. O., Lin, C.
S., and Lue, T. F. (2007). Upregulation of penile brain-derived neurotrophic factor (BDNF) and activation of the JAK/STAT signalling pathway in the major pelvic ganglion of the rat after cavernous nerve transection. Eur. Urol. 52, 574-580.

Bremer, M., Fröb F, Kichko, T., Reeh, P., Tamm, E. R., Suter, U., and Wegner, M. (2011). Sox10 is required for Schwann-cell homeostasis and myelin maintenance in the adult peripheral nerve. Glia 59, 1022-1032. 
Britsch, S., Goerich, D. E., Riethmacher, D., Peirano, R. I., Rossner, M., Nave, K. A., Birchmeier, C., and Wegner, M. (2001). The transcription factor Sox10 is a key regulator of peripheral glial development. Genes Dev. $15,66-78$.

Callahan, T., Young, H. M., Anderson, R. B., Enomoto, H., and Anderson, C. R. (2008). Development of satellite glia in mouse sympathetic ganglia: GDNF and GFR alpha 1 are not essential. Glia 56, 1428-1437.

Cartier, A. E., Djakovic, S. N., Salehi, A., Wilson, S. M., Masliah, E., and Patrick, G. N. (2009). Regulation of synaptic structure by ubiquitin Cterminal hydrolase L1. J. Neurosci. 29, 7857-7868.

Choi, M. Y., Romer, A. I., Hu, M., Lepourcelet, M., Mechoor, A., Yesilaltay, A., Krieger, M., Gray, P. A., and Shivdasani, R. A. (2006). A dynamic expression survey identifies transcription factors relevant in mouse digestive tract development. Development 133, 4119-4129.

Collombat, P., Mansouri, A., HecksherSorensen, J., Serup, P., Krull, J., Gradwohl, G., and Gruss, P. (2003). Opposing actions of Arx and Pax4 in endocrine pancreas development. Genes Dev. 17, 2591-2603.

Corpening, J. C., Cantrell, V. A., Deal, K. K., and Southard-Smith, E. M. (2008). A Histone2BCerulean BAC transgene identifies differential expression of Phox $2 b$ in migrating enteric neural crest derivatives and enteric glia. Dev. Dyn. 237, 1119-1132.

Corpening, J. C., Deal, K. K., Cantrell, V. A., Skelton, S. B., Buehler, D. P., and Southard-Smith, E. M. (2011). Isolation and live imaging of enteric progenitors based on Sox10Histone2BVenus transgene expression. Genesis 49, 599-618.

D'Autreaux, F., Morikawa, Y., Cserjesi, P., and Gershon, M. D. (2007). Hand2 is necessary for terminal differentiation of enteric neurons from crest-derived precursors but not for their migration into the gut or for formation of glia. Development 134, 2237-2249.

Diez-Roux, G., Banfi, S., Sultan, M., Geffers, L., Anand, S., Rozado, D., Magen, A., Canidio, E., Pagani, M., Peluso, I., Lin-Marq, N., Koch, M., Bilio, M., Cantiello, I., Verde, R., De Masi, C., Bianchi, S. A., Cicchini, J., Perroud, E., Mehmeti, S., Dagand, E., Schrinner, S., Nürnberger, A., Schmidt, K., Metz, K., Zwingmann, C., Brieske, N., Springer, C., Hernandez, A. M., Herzog, S., Grabbe, F., Sieverding, C., Fischer, B., Schrader,
K., Brockmeyer, M., Dettmer, S., Helbig, C., Alunni, V., Battaini, M. A., Mura, C., Henrichsen, C. N., GarciaLopez, R., Echevarria, D., Puelles, E., Garcia-Calero, E., Kruse, S., Uhr, M., Kauck, C., Feng, G., Milyaev, N., Ong, C. K., Kumar, L., Lam, M., Semple, C. A., Gyenesei, A., Mundlos, S., Radelof, U., Lehrach, H., Sarmientos, P., Reymond, A., Davidson, D. R., Dollé P, Antonarakis, S. E., Yaspo, M. L., Martinez, S., Baldock, R. A., Eichele, G., and Ballabio, A. (2011). A high-resolution anatomical atlas of the transcriptome in the mouse embryo. PLoS Biol. 9, e1000582. doi:10.1371/journal.pbio.1000582

Dixon, J. S., Jen, P. Y., and Gosling, J. A. (1998). Immunohistochemical characteristics of human paraganglion cells and sensory corpuscles associated with the urinary bladder. A developmental study in the male fetus, neonate and infant. J. Anat. 192(Pt 3), 407-415.

Elbadawi, A. (1991). Anatomy and Innervation of the Vesicourethral Muscular Unit of Micturition. Boston: Little, Brown, and Company.

Enomoto, H., Araki, T., Jackman, A., Heuckeroth, R. O., Snider, W. D., Johnson, E. M. Jr., and Milbrandt, J. (1998). GFR alpha1-deficient mice have deficits in the enteric nervous system and kidneys. Neuron 21 , 317-324.

Fairman, C. L., Clagett-Dame, M., Lennon, V. A., and Epstein, M. L. (1995). Appearance of neurons in the developing chick gut. Dev. Dyn. 204, 192-201.

Fang, J., Chung, Y. W., and Clemens, L. G. (2000). Relation of Fos-IR expression in the pelvic ganglion to sexual behavior in laboratory rats. Behav. Neurosci. 114, 543-552.

Fu, H., Cai, J., Clevers, H., Fast, E., Gray, S., Greenberg, R., Jain, M. K., Ma, Q., Qiu, M., Rowitch, D. H., Taylor, C. M., and Stiles, C. D. (2009). A genome-wide screen for spatially restricted expression patterns identifies transcription factors that regulate glial development. J. Neurosci. 29, 11399-11408.

Gao, Z., Ure, K., Ding, P., Nashaat, M., Yuan, L., Ma, J., Hammer, R. E., and Hsieh, J. (2011). The master negative regulator REST/NRSF controls adult neurogenesis by restraining the neurogenic program in quiescent stem cells. J. Neurosci. 31, 9772-9786.

Girard, B. M., Malley, S. E., Braas, K. M., May, V., and Vizzard, M. A. (2010). PACAP/VIP and receptor characterization in micturition pathways in mice with overexpression of NGF in urothelium. J. Mol. Neurosci. 42, 378-389.

Gray, P. A., Fu, H., Luo, P., Zhao, Q., Yu, J., Ferrari, A., Tenzen, T., Yuk, D. I., Tsung, E. F., Cai, Z., Alberta, J. A., Cheng, L. P., Liu, Y., Stenman, J. M., Valerius, M. T., Billings, N., Kim, H. A., Greenberg, M. E., McMahon, A. P., Rowitch, D. H., Stiles, C. D., and Ma, Q. (2004). Mouse brain organization revealed through direct genome-scale TF expression analysis. Science 306, 2255-2257.

Hang, Y., and Stein, R. (2011). MafA and MafB activity in pancreatic beta cells. Trends Endocrinol. Metab. 22, 364-373.

Harding, S. D., Armit, C., Armstrong, J., Brennan, J., Cheng, Y., Haggarty, B., Houghton, D., Lloyd-MacGilp, S., Pi, X., Roochun, Y., Sharghi, M., Tindal, C., McMahon, A. P., Gottesman, B. Little, M. H., Georgas, K., Aronow, B. J., Potter, S. S., Brunskill, E. W., Southard-Smith, E. M., Mendelsohn, C., Baldock, R. A., Davies, J. A., and Davidson, D. (2011). The GUDMAP database - an online resource for genitourinary research. Development 138, 2845-2853.

Hendershot, T. J., Liu, H., Sarkar, A. A., Giovannucci, D. R., Clouthier, D. E., Abe, M., and Howard, M. J. (2007). Expression of Hand2 is sufficient for neurogenesis and cell type-specific gene expression in the enteric nervous system. Dev. Dyn. 236, 93-105.

Hu He, K. H., Lorenzo, P. I., Brun, T. Jimenez Moreno, C. M., Aeberhard, D., Vallejo Ortega, J., Cornu, M., Thorel, F., Gjinovci, A., Thorens, B., Herrera, P. L., Meda, P., Wollheim, C. B., and Gauthier, B. R. (2011). In vivo conditional Pax4 overexpression in mature islet beta-cells prevents stress-induced hyperglycemia in mice. Diabetes 60, 1705-1715.

Hunt, D., Coffin, R. S., and Anderson, P. N. (2002). The Nogo receptor, its ligands and axonal regeneration in the spinal cord: a review. J. Neurocytol. 31, 93-120.

Ichikawa, T., Ajiki, K., Matsuura, J. and Misawa, H. (1997). Localization of two cholinergic markers, choline acetyltransferase and vesicular acetylcholine transporter in the central nervous system of the rat: in situ hybridization histochemistry and immunohistochemistry. $J$. Chem. Neuroanat. 13, 23-39.

Iuchi, H., Satoh, Y., and Ono, K. (1994). Postnatal development of neuropeptide Y- and calcitonin gene-related peptide-immunoreactive nerves in the rat urinary bladder. Anat. Embryol. 189, 361-73.
Iwashita, T., Kruger, G. M., Pardal, R., Kiel, M. J., and Morrison, S. J. (2003). Hirschsprung disease is linked to defects in neural crest stem cell function. Science 301, 972-976.

Jacquet, B. V., Muthusamy, N., Sommerville, L. J., Xiao, G., Liang, H., Zhang, Y., Holtzman, M. J., and Ghashghaei, H. T. (2011). Specification of a Foxj1-dependent lineage in the forebrain is required for embryonic-to-postnatal transition of neurogenesis in the olfactory bulb. J. Neurosci. 31, 9368-9382.

Jen, P. Y., Dixon, J. S., and Gosling, J. A. (1995). Immunohistochemical localization of neuromarkers and neuropeptides in human fetal and neonatal urinary bladder. Br. J. Urol. $75,230-235$.

Jobling, P., and Lim, R. (2008). Anatomical and physiological properties of pelvic ganglion neurons in female mice. Auton. Neurosci. 140, 30-39.

Karalay, O., Doberauer, K., Vadodaria, K. C., Knobloch, M., Berti, L., Miquelajauregui, A., Schwark, M., Jagasia, R., Taketo, M. M., Tarabykin, V., Lie, D. C., and Jessberger, S. (2011). Prospero-related homeobox 1 gene (Proxl) is regulated by canonical Wnt signaling and has a stagespecific role in adult hippocampal neurogenesis. Proc. Natl. Acad. Sci. U.S.A. 108, 5807-5812.

Karam, I., Droupy, S., Abd-Alsamad, I., Uhl, J. F., Benoît, G., and Delmas, V. (2005). Innervation of the female human urethral sphincter: $3 \mathrm{D}$ reconstruction of immunohistochemical studies in the fetus. Eur Urol. 47, 627-633; discussion 634 .

Keast, J. R. (2006). Plasticity of pelvic autonomic ganglia and urogenital innervation. Int. Rev. Cytol. 248, 141-208.

Kiers, L., Altermatt, H. J., and Lennon, V. A. (1991). Paraneoplastic antineuronal nuclear IgG autoantibodies (type I) localize antigen in small cell lung carcinoma. Mayo Clin. Proc. 66, 1209-1216.

Kim, J., Lo, L., Dormand, E., and Anderson, D. J. (2003). SOX10 maintains multipotency and inhibits neuronal differentiation of neural crest stem cells. Neuron 38, 17-31.

Kitaguchi, T., Nakata, K., Nagai, T., Aruga, J., and Mikoshiba, K. (2001). Xenopus Polycomblike 2 (XPcl2) controls anterior to posterior patterning of the neural tissue. Dev. Genes Evol. 211, 309-314.

Kluck, P. (1980). The autonomic innervation of the human urinary bladder, bladder neck and urethra: a histochemical study. Anat. Rec. 198, 439-447. 
Kong, Y. M., Macdonald, R. J., Wen, X., Yang, P., Barbera, V. M., and Swift, G. H. (2006). A comprehensive survey of DNA-binding transcription factor gene expression in human fetal and adult organs. Gene Expr. Patterns 6, 678-686.

Lee, A. P., Yang, Y., Brenner, S., and Venkatesh, B. (2007). TFCONES: a database of vertebrate transcription factor-encoding genes and their associated conserved noncoding elements. BMC Genomics 8, 441. doi:10.1186/1471-2164-8-441

Lee, K. C., Sharma, S., Tuttle, J. B., and Steers, W. D. (2010). Origin and characterization of retrograde labeled neurons supplying the rat urethra using fiberoptic confocal fluorescent microscopy in vivo and immunohistochemistry. J. Urol. 184, 1550-1554.

Lei, J., and Howard, M. J. (2011). Targeted deletion of Hand2 in enteric neural precursor cells affects its functions in neurogenesis, neurotransmitter specification and gangliogenesis, causing functional aganglionosis. Development 138, 4789-4800.

Li, X., Sun, C., Lin, C., Ma, T., Madhavan, M. C., Campbell, K., and Yang, Z. (2011). The transcription factor $\mathrm{Sp} 8$ is required for the production of parvalbumin-expressing interneurons in the olfactory bulb. $J$. Neurosci. 31, 8450-8455.

Little, M. H., Brennan, J., Georgas, K., Davies, J. A., Davidson, D. R., Baldock, R. A., Beverdam, A., Bertram, J. F., Capel, B., Chiu, H. S., Clements, D., Cullen-McEwen, L., Fleming, J., Gilbert, T., Herzlinger, D., Houghton, D., Kaufman, M. H., Kleymenova, E., Koopman, P. A., Lewis, A. G., McMahon, A. P., Mendelsohn, C. L., Mitchell, E. K., Rumballe, B. A., Sweeney, D. E., Valerius, M. T., Yamada, G., Yang, Y., and Yu, J. (2007). A highresolution anatomical ontology of the developing murine genitourinary tract. Gene Expr. Patterns 7, 680-699.

Liu, J., Hunter, C. S., Du, A., Ediger, B., Walp, E., Murray, J., Stein, R., and May, C. L. (2011). Islet-1 regulates Arx transcription during pancreatic islet alpha-cell development. J. Biol. Chem. 286, 15352-15360.

Lu, Q. R., Yuk, D., Alberta, J. A., Zhu, Z., Pawlitzky, I., Chan, J., McMahon, A. P., Stiles, C. D., and Rowitch, D. H. (2000). Sonic hedgehog - regulated oligodendrocyte lineage genes encoding bHLH proteins in the mammalian central nervous system. Neuron 25, 317-329.
Magdaleno, S., Jensen, P., Brumwell, C. L., Seal, A., Lehman, K., Asbury, A., Cheung, T., Cornelius, T., Batten, D. M., Eden, C., Norland, S. M., Rice, D. S., Dosooye, N., Shakya, S., Mehta, P., and Curran, T. (2006). BGEM: an in situ hybridization database of gene expression in the embryonic and adult mouse nervous system. PLoS Biol. 4, e86. doi:10.1371/journal.pbio.0040086

Mark, M., Lufkin, T., Vonesch, J. L., Ruberte, E., Olivo, J. C., Dollé, P., Gorry, P., Lumsden, A., and Chambon, P. (1993). Two rhombomeres are altered in Hoxa-1 mutant mice. Development 119, 319-338.

McKinney, M. C., and Kulesa, P. M. (2011). In vivo calcium dynamics during neural crest cell migration and patterning using GCaMP3. Dev. Biol. 358, 309-317.

McMahon, A. P., Aronow, B. J., Davidson, D. R., Davies, J. A., Gaido, K. W., Grimmond, S., Lessard, J. L., Little, M. H., Potter, S. S., Wilder, E. L., Zhang, P., and GUDMAP Project. (2008). GUDMAP: the genitourinary developmental molecular anatomy project. J. Am. Soc. Nephrol. $19,667-671$.

Morrison, S. J., White, P. M., Zock, C., and Anderson, D. J. (1999). Prospective identification, isolation by flow cytometry, and in vivo self-renewal of multipotent mammalian neural crest stem cells. Cell 96, 737-749.

Mugford, J. W., Yu, J., Kobayashi, A., and McMahon, A. P. (2009). Highresolution gene expression analysis of the developing mouse kidney defines novel cellular compartments within the nephron progenitor population. Dev. Biol. 333, 312-323.

Muller, F., and Rohrer, H. (2002). Molecular control of ciliary neuron development: BMPs and downstream transcriptional control in the parasympathetic lineage. Development 129, 5707-5717.

Mundell, N. A., Plank, J. L., LeGrone, A. W., Frist, A. Y., Zhu, L., Shin, M. K., Southard-Smith, E. M., and Labosky, P. A. (2012). Enteric nervous system specific deletion of Foxd3 disrupts glial cell differentiation and activates compensatory enteric progenitors. Dev. Biol. 363, 373-387.

Nangle, M. R., and Keast, J. R. (2009). Deafferentation and axotomy each cause neurturin-independent upregulation of c-Jun in rodent pelvic ganglia. Exp. Neurol. 215, 271-280.

Nishi, R., Stubbusch, J., Hulce, J. J., Hruska, M., Pappas, A., Bravo, M. C., Huber, L. P., Bakondi, B., Soltys, J., and Rohrer, H. (2010). The cortistatin gene PSS2 rather than the somatostatin gene PSS1 is strongly expressed in developing avian autonomic neurons. J. Comp. Neurol. $518,839-850$

Pan, F. C., and Wright, C. (2011). Pancreas organogenesis: from bud to plexus to gland. Dev. Dyn. 240, 530-565.

Papka, R. E., Storey-Workley, M., Shughrue, P. J., Merchenthaler, I., Collins, J. J., Usip, S., Saunders, P. T., and Shupnik, M. (2001) Estrogen receptor-alpha and betaimmunoreactivity and mRNA in neurons of sensory and autonomic ganglia and spinal cord. Cell Tissue Res. 304, 193-214.

Paratore, C., Goerich, D. E., Suter, U., Wegner, M., and Sommer, L. (2001). Survival and glial fate acquisition of neural crest cells are regulated by an interplay between the transcription factor Sox 10 and extrinsic combinatorial signaling. Development 128 , 3949-3961.

Pattyn, A., Morin, X., Cremer, H., Goridis, C., and Brunet, J. F. (1999). The homeobox gene Phox $2 \mathrm{~b}$ is essential for the development of autonomic neural crest derivatives. Nature 399, 366-370.

Peddie, C. J., and Keast, J. R. (2011) Pelvic nerve injury causes a rapid decrease in expression of choline acetyltransferase and upregulation of c-Jun and ATF-3 in a distinct population of sacral preganglionic neurons. Front. Neurosci. 5:6. doi:10.3389/fnins.2011.00006

Sakurai, M., Ayukawa, K., Setsuie, R., Nishikawa, K., Hara, Y., Ohashi, H., Nishimoto, M., Abe, T., Kudo, Y., Sekiguchi, M., Sato, Y., Aoki, S. Noda, M., and Wada, K. (2006). Ubiquitin C-terminal hydrolase L1 regulates the morphology of neural progenitor cells and modulates their differentiation. J. Cell. Sci. 119, 162-171.

Schirar, A., Chang, C., and Rousseau, J. P. (1997). Localization of androgen receptor in nitric oxide synthaseand vasoactive intestinal peptidecontaining neurons of the major pelvic ganglion innervating the rat penis. J. Neuroendocrinol. 9, 141-150.

Sham, M. H., Vesque, C., Nonchev, S., Marshall, H., Frain, M., Gupta, R. D., Whiting, J., Wilkinson, D., Charnay, P., and Krumlauf, R. (1993). The zinc finger gene Krox20 regulates HoxB2 (Hox2.8) during hindbrain segmentation. Cell 72, 183-196.

Shen, L., Zhao, Z. Y., Wang, Y. Z., Ji, S. P., Liu, X. P., Liu, X. W., Che,
H. L., Lin, W., Li, X., Zhang, J., and Yao, L. B. (2008). Immunohistochemical detection of $\mathrm{Ndrg} 2$ in the mouse nervous system. Neuroreport $19,927-931$.

Sidebotham, E. L., Woodward, M. N., Kenny, S. E., Lloyd, D. A., Vaillant, C. R., and Edgar, D. H. (2001). Assessment of protein gene product 9.5 as a marker of neural crest-derived precursor cells in the developing enteric nervous system. Pediatr. Surg. Int. 17, 304-307.

Skarnes, W. C., Rosen, B., West, A. P., Koutsourakis, M., Bushell, W., Iyer, V., Mujica, A. O., Thomas, M., Harrow, J., Cox, T., Jackson, D., Severin J., Biggs, P., Fu, J., Nefedov, M., de Jong, P. J., Stewart, A. F., and Bradley, A. (2011). A conditional knockout resource for the genome-wide study of mouse gene function. Nature 474 , $337-342$.

Soreq, H., and Seidman, S. (2001) Acetylcholinesterase - new roles for an old actor. Nat. Rev. Neurosci. 2, 294-302.

Southard-Smith, E. M., Kos, L., and Pavan, W. J. (1998). Sox10 mutation disrupts neural crest development in Dom Hirschsprung mouse model. Nat. Genet. 18, 60-64.

Stewart, A. L., Anderson, R. B., Kobayashi, K., and Young, H. M. (2008). Effects of NGF, NT-3 and GDNF family members on neurite outgrowth and migration from pelvic ganglia from embryonic and newborn mice. BMC Dev. Biol. 8, 73 . doi:10.1186/1471-213X-8-73

Takeichi, T., Takarada-Iemata, M., Hashida, K., Sudo, H., Okuda, T., Kokame, K., Hatano, T., Takanashi, M., Funabe, S., Hattori, N., Kitamura, O., Kitao, Y., and Hori, O. (2011). The effect of Ndrg2 expression on astroglial activation. Neurochem. Int. 59, 21-27.

Taylor, A., Namdarian, B., Corcoran, $\mathrm{H}$. Hovens, C., and Costello, A. (2010). Fluorescent nerve tracers: illuminating pelvic surgical neuro-anatomy. $J$. Urol. 183, e269.

Thompson, R. J., Doran, J. F., Jackson, P., Dhillon, A. P., and Rode, J. (1983). PGP 9.5 - a new marker for vertebrate neurons and neuroendocrine cells. Brain Res. 278, 224-228.

Tomotsune, D., Shirai, M., Takihara, Y., and Shimada, K. (2000). Regulation of Hoxb3 expression in the hindbrain and pharyngeal arches by rae28, a member of the mammalian Polycomb group of genes. Mech. Dev. 98, $165-169$.

Tompkins, J. D., Girard, B. M., Vizzard, M. A., and Parsons, R. L. (2010). 
VIP and PACAP effects on mouse major pelvic ganglia neurons. J. Mol. Neurosci. 42, 390-396.

Tsarovina, K., Schellenberger, J., Schneider, C., and Rohrer, H. (2008). Progenitor cell maintenance and neurogenesis in sympathetic ganglia involves Notch signaling. Mol. Cell. Neurosci. 37, 20-31.

van de Putte, T., Francis, A., Nelles, L., van Grunsven, L. A., and Huylebroeck, D. (2007). Neural crestspecific removal of $\mathrm{Zfhx} 1 \mathrm{~b}$ in mouse leads to a wide range of neurocristopathies reminiscent of MowatWilson syndrome. Hum. Mol. Genet. 16, 1423-1436.

Wadhwa, S., and Bijlani, V. (1983). Prenatal development of the autonomic innervation of the human urinary bladder. Indian J. Med. Res. 77, 401-408.

Wallner, C., Dabhoiwala, N. F., DeRuiter, M. C., and Lamers, W. H. (2009). The anatomical components of urinary continence. Eur. Urol. 55, 932-943.

Walters, L. C., Cantrell, V. A., Weller, K. P., Mosher, J. T., and SouthardSmith, E. M. (2010). Genetic background impacts developmental potential of enteric neural crest-derived progenitors in the
Sox10Dom model of Hirschsprung disease. Hum. Mol. Genet. 19, 4353-4372.

Wanigasekara, Y., Kepper, M. E., and Keast, J. R. (2003). Immunohistochemical characterisation of pelvic autonomic ganglia in male mice. Cell Tissue Res. 311, 175-185.

White, P. M., Morrison, S. J., Orimoto, K., Kubu, C. J., Verdi, J. M., and Anderson, D. J. (2001). Neural crest stem cells undergo cell-intrinsic developmental changes in sensitivity to instructive differentiation signals. Neuron 29, 57-71.

Yamamoto, H., Kokame, K., Okuda, T., Nakajo, Y., Yanamoto, H., and Miyata, T. (2011). NDRG4 proteindeficient mice exhibit spatial learning deficits and vulnerabilities to cerebral ischemia. J. Biol. Chem. 286, 26158-26165.

Yan, H., and Keast, J. R. (2008). Neurturin regulates postnatal differentiation of parasympathetic pelvic ganglion neurons, initial axonal projections, and maintenance of terminal fields in male urogenital organs. J. Comp. Neurol. 507, 1169-1183.

Young, H. M., Bergner, A. J., and Muller, T. (2003). Acquisition of neuronal and glial markers by neural crestderived cells in the mouse intestine. J. Comp. Neurol. 456, 1-11.

Yu, J., Valerius, M. T., Duah, M. Staser, K., Hansard, J. K., Guo, J. J., McMahon, J., Vaughan, J., Faria, D., Georgas, K., Rumballe, B., Ren, Q., Krautzberger, A. M., Junker, J. P., Thiagarajan, R. D., Machanick, P., Gray, P. A., van Oudenaarden, A., Rowitch, D. H., Stiles, C. D., Ma, Q., Grimmond, S. M., Bailey, T. L., Little, M. H., and McMahon, A. P. (2012). Identification of molecular compartments and genetic circuitry in the developing mammalian kidney. Development 139, 1863-1873.

Yucel, S., Liu, W., Cordero, D., Donjacour, A., Cunha, G., and Baskin, L. S. (2004). Anatomical studies of the fibroblast growth factor-10 mutant, Sonic Hedge Hog mutant and androgen receptor mutant mouse genital tubercle. Adv. Exp. Med. Biol. 545, 123-148.

Zvarova, K., and Vizzard, M. A. (2005). Distribution and fate of cocaineand amphetamine-regulated transcript peptide (CARTp)-expressing cells in rat urinary bladder: a developmental study. J. Comp. Neurol. 489, 501-517.
Conflict of Interest Statement: The authors declare that the research was conducted in the absence of any commercial or financial relationships that could be construed as a potential conflict of interest.

Received: 08 February 2012; accepted: 22 August 2012; published online: 12 September 2012.

Citation: Wiese CB, Ireland S, Fleming NL, Yu J, Valerius MT, Georgas K, Chiu HS, Brennan J, Armstrong J, Little MH, McMahon AP and SouthardSmith EM (2012) A genome-wide screen to identify transcription factors expressed in pelvic ganglia of the lower urinary tract. Front. Neurosci. 6:130. doi: 10.3389/fnins.2012.00130

This article was submitted to Frontiers in Autonomic Neuroscience, a specialty of Frontiers in Neuroscience.

Copyright () 2012 Wiese, Ireland, Fleming, Yu, Valerius, Georgas, Chiu, Brennan, Armstrong, Little, McMahon and Southard-Smith. This is an open-access article distributed under the terms of the Creative Commons Attribution License, which permits use, distribution and reproduction in other forums, provided the original authors and source are credited and subject to any copyright notices concerning any third-party graphics etc. 